\title{
La Relevancia Macroeconómica de los Bienes Raíces en México
}

\author{
Alfonso H. Guerra de Luna \\ Diciembre de 1997 \\ Documento de Investigación No. 9707 \\ Dirección General de Investigación Económica \\ BANCO DE MÉXICO
}

\begin{abstract}
Alfonso H. Guerra de Luna
(Investigador Económico, Dirección de Estudios Económicos, Banco de México. Aguerra@ banxico.org.mx)

El autor agradece los comentarios de Daniel Backal, Juan Pablo Graf, Gerardo Jacobs, José Antonio Murillo, Alejandro Pérez López, Moisés Schwartz y Abraham Vela; los errores y omisiones son responsabilidad única del autor.
\end{abstract}

\section{BANCO DE MÉXICO}

(El contenido de este documento no refleja necesariamente la opinión del Banco de México.)

\section{RESUMEN}

La evidencia empírica demuestra que el mercado de bienes raíces tiene un comportamiento cíclico. Cambios en los precios de estos activos pueden tener repercusiones para la economía en su conjunto siendo el sistema financiero uno de los canales de mayor importancia. La literatura que analiza el problema del crédito hipotecario señala que el factor determinante de la decisión de moratoria es el valor de la vivienda neto del monto de la hipoteca, o sea el capital neto en vivienda. El presente trabajo sustenta esta hipótesis para el caso de México al analizar la relación entre la razón de crédito a valor de la vivienda (variable representativa del capital neto en vivienda) y la cartera hipotecaria vencida. Es probable que gran parte de la expansión crediticia en México se dio cuando la probabilidad de suspensión de pagos era relativamente alta y que el problema hipotecario se gestó con antelación a la crisis de 1994. 


\section{Contenido}

Introducción

1. Los Bienes Raíces: una Perspectiva Internacional

2. La Hipoteca como una Opción de Venta

3. La Hipoteca Mexicana con Tasa Dual

4 La Determinación del Alquiler en México: una Visión Macroeconómica

4.1 La Demanda de Servicios de Vivienda: un Análisis Tradicional

4.2 La Determinación del Alquiler Utilizando Variables Macroeconómicas

5. La Evolución del Precio de los Terrenos Urbanos en México

6 El problema de la Cartera Hipotecaria en México

6.1 La Tasa de Rendimiento de un Bien Raíz comprado con una Hipoteca

6.2 La Relación entre la Cartera Hipotecaria Vencida y la Razón de Crédito a Valor del Bien Raíz

6.3 La Probabilidad de Moratoria a lo Largo del Ciclo Crediticio

Conclusiones

Referencias

Anexo Estadístico

\section{Lista de Gráficas}

Gráfica 1.1 Precio Real de la vivienda. Evidencia Internacional

Gráfica 3.1 Evolución del Valor de una Hipoteca Comparado con el Precio de una Casa

Gráfica 4.1 México: Índice Real de la Renta de Vivienda y Transferencia Neta de Recursos (1970-1995

Gráfica 5.1 Precio de las Casas y de la Tierra Urbana

Gráfica 5.2 Índice Real de Precios y Cotizaciones de la Bolsa Mexicana de Valores

Gráfica 5.3 Precio Real de la Tierra Urbana y Alquiler Real (Ciudad de México

Gráfica 6.1 Tasa de Rendimiento Real de un Bien Raíz Comprado con una Hipoteca Bajo Distintos Supuestos de la Razón Inicial de Crédito/Valor del Bien Raíz.

Gráfica 6.2 Crédito Hipotecario: Cartera Vencida y Cartera con Capital neto Negativo

Gráfica 6.3 Función no Lineal entre la Razón Monto de Crédito/Valor de la Vivienda y la Probabilidad de no Pago 
Gráfica 6.4 Cartera Vencida como Porcentaje de la Cartera Total y Probabilidad de no Pago

Gráfica 6.5 Evolución del Valor de un Crédito Hipotecario y de un Terreno Urbano

\section{Lista de Cuadros}

Cuadro 1.1 Valor del Acervo de Vivienda y del Mercado Accionario

Cuadro 4.1 Estimación de Demanda de Vivienda: Mínimos Cuadrados Ordinarios

Cuadro 4.2 Pruebas de Cointegración: Demanda de Vivienda

Cuadro 4.3 Estimación de la Renta de Vivienda: Mínimos Cuadrados Ordinarios

Cuadro 4.4 Pruebas de Cointegración: Renta de Vivienda

Cuadro 5.1 Relación entre el Precio Real de los Terrero Urbanos y el Arriendo Real 


\section{La Relevancia Macroeconómica de los Bienes Raíces en México}

\section{Introducción}

Durante la segunda mitad de la década de los ochenta, un número importante de países experimentó un incremento sostenido en el precio de los bienes raíces. A la par de este proceso, el crédito hipotecario aumentó sustancialmente. Al finalizar la década, los precios de las casas y terrenos comenzaron a disminuir erosionando gran parte del incremento anterior. Existen diversas hipótesis sobre el origen del ciclo inmobiliario, sin embargo, no se ha logrado un consenso al respecto. En donde si existe una convergencia de opiniones, es en señalar que las crisis hipotecarias en distintos países han tenido repercusiones macroeconómicas importantes. El caso del Reino Unido es un ejemplo: se estima que un millón de familias cuentan con un crédito hipotecario cuyo saldo es superior al valor de su casa.

Los países en vías de desarrollo no han estado exentos de los ciclos inmobiliarios. A finales de la década de los setenta en Chile y Uruguay, los precios de las casas aumentaron en un 100\% y disminuyeron en una magnitud similar en tan sólo cinco años. Asimismo, las recientes crisis bancarias en varios países asiáticos están en gran parte relacionadas con inversiones en bienes raíces cuyos precios se desplomaron.

En México, los bienes raíces también han tenido un papel importante en la crisis financiera. A principios de 1997 la cartera vencida hipotecaria representó una parte significativa del total de la cartera vencida. El problema hipotecario es un asunto grave que no solamente se circunscribe al ámbito financiero. Dicho problema representa para miles de familias mexicanas una restricción real sobre sus posibilidades de desarrollo económico. Además, gran parte de estas familias se encuentran al inicio de su ciclo de vida económico y su vivienda es, por mucho, la parte más importante de su riqueza.

La literatura empírica que analiza el problema de la cartera vencida hipotecaria señala que:

"...existe considerable evidencia empírica, la cual muestra que es el valor de la casa comparado con el de la hipoteca, en lugar de características personales como la posición de liquidez del dueño de la casa, la que explica la suspensión de pagos." (Kau, Keenan y Kim (1991) página ocho. Citados por Case, Shiller y Weiss (1995). Traducción del autor.)

Esta afirmación implica que es el valor de la vivienda neto del monto de la hipoteca, o sea el capital neto en vivienda, el factor determinante de la decisión de moratoria. Esto se confirma con la estrategia que recientemente ha seguido la banca comercial en México, la cual ha instrumentado programas basados en este concepto para incentivar el pago de la cartera hipotecaria. La hipótesis que sustenta este trabajo es que el determinante principal del problema de la cartera hipotecaria en México es el capital neto en vivienda, y no tanto, o exclusivamente, cambios en la capacidad de pago de los deudores. La secuencia lógica del trabajo tiene por objetivo demostrar que en un 
entorno macroeconómico inestable se pueden generar ciclos pronunciados en los precios de los bienes raíces, y que estos ciclos pueden en poco tiempo erosionar el capital neto en vivienda, el cual es determinante fundamental de la decisión de moratoria. En la segunda sección del trabajo se presentan los argumentos teóricos que sustentan esta última hipótesis utilizando conceptos relacionados con la teoría de las opciones.

Con la finalidad de poner en contexto la discusión sobre el caso mexicano, en la primera sección del trabajo se hace una comparación entre países sobre el comportamiento de los precios de los bienes raíces y del mercado hipotecario. Empieza la sección por estimar el valor del acervo de vivienda para un grupo de países en vías de desarrollo, encontrándose que las construcciones residenciales representan alrededor de una tercera parte de la riqueza total. Además, se enumeran una serie de regularidades empíricas del mercado inmobiliario, sobresaliendo el hecho de que los precios de los bienes raíces tienen un comportamiento cíclico.

En el estudio de la cartera vencida es importante analizar la dinámica tanto del valor de la casa como del saldo del crédito hipotecario. En la mayoría de los países, el análisis se concentra en el valor de la casa pues el crédito hipotecario, en términos reales, siempre disminuye conforme pasa el tiempo. Sin embargo, en el caso de México el análisis es más complicado ya que la mayoría de los créditos hipotecarios refinanciaban parte de los intereses, lo cual hacía más probable un aumento en el saldo real de la hipoteca durante los primeros años del crédito. En particular, un aumento en la tasa de interés se traducía en un refinanciamiento mayor, o sea un incremento en el saldo que a su vez erosionaba el capital neto en vivienda. En la sección sobre la hipoteca de tasa dual se discute sobre estos temas y se describe la hipoteca mexicana.

Tomando como guía la hipótesis de que el capital neto en vivienda es el determinante fundamental del problema de la cartera vencida, el trabajo cubre dos grandes temas. El primero, se refiere a la determinación del arriendo de vivienda y de los precios de los bienes raíces en México (secciones cuatro y cinco). El segundo, es aportar evidencia empírica para sustentar la hipótesis de que el capital neto en vivienda es el determinante principal de la decisión de moratoria (sección seis). El primer tema comienza por investigar la determinación del arriendo utilizando variables macroeconómicas, tales como el ingreso y los flujos de capitales. Se continua analizando la forma en que los precios de los bienes raíces reaccionan a las condiciones del mercado inmobiliario.

El segundo tema inicia con una estimación del capital neto en vivienda para el conjunto de la cartera hipotecaria mexicana. Se presenta evidencia empírica sobre la relación entre la razón crédito a valor de la vivienda y la cartera vencida. Ya que los bienes raíces tienen un comportamiento cíclico, la probabilidad de moratoria dependerá de la parte del ciclo en que se otorgue el crédito. Adicionalmente, dadas las características de los esquemas crediticios hipotecarios en México, el aumento en la tasa de interés real a finales de 1992 generó un incremento en el refinanciamiento de los saldos hipotecarios. Se encuentra que gran parte de la expansión crediticia se dio cuando la probabilidad de suspensión de pagos era relativamente alta.

Es importante señalar que en México se da un incremento sustancial en los créditos vencidos, mucho antes de la crisis iniciada en diciembre de 1994. Frecuentemente esta última es señalada como la causa principal del problema hipotecario. Sin embargo, una parte importante de la cartera hipotecaria llegó a finales de 1994 con capital neto negativo o cercano a serlo. El problema de la cartera hipotecaria ya se había gestado, la crisis le dio el ambiente propicio para desarrollarse.

El análisis que se presenta es relevante para un Banco Central ya que está relacionado con el sano desarrollo del sistema financiero. Por otro lado, el estudio de la dinámica de los precios de los bienes raíces puede dar una perspectiva que simplemente otro análisis a nivel microeconómico es 
incapaz dar - se trata de investigar los efectos que variables macroeconómicas tienen, a través del mercado de bienes raíces, sobre el riesgo sistémico de los bancos - .

\section{1.- Los Bienes Raíces: una perspectiva internacional.}

Gran parte de los estudios sobre el tema de bienes raíces inician argumentando sobre la importancia relativa de los bienes inmuebles en la riqueza de una nación. Este trabajo no será la excepción. Sin embargo, en esta sección se refuerza este argumento haciendo énfasis sobre el papel que juegan las casas y terrenos como colateral y el comportamiento cíclico de sus precios. La combinación de estas características (peso relativo en la riqueza total, papel como colateral y precios fluctuantes) confieren a los bienes raíces la posibilidad de ser actores importantes en una crisis financiera.

Esta sección presenta una serie de regularidades empíricas observadas en diversos países. Su enumeración tiene como objetivo poner en contexto la discusión sobre el caso de México y sostener lo argumentado en el párrafo anterior. No se analiza con detenimiento las aseveraciones hechas en cada inciso. Para un descripción más detallada de estas regularidades empíricas véase Guerra (1997).

a) Las estructuras residenciales representan una parte sustancial de la riqueza de una nación. El cuadro 1.1 presenta una estimación del valor de las construcciones residenciales

(las cuales excluyen el valor de la tierra) tanto para un grupo de países desarrollados como en desarrollo. (Un anexo describiendo la metodología utilizada para estimar los acervos de vivienda se encuentra disponible. Metodologías similares pueden ser consultadas en Harberger (1969) y Cervini (1995).) Es posible observar que el valor de las estructuras residenciales representó, al final de 1990, entre el $85 \%$ y el $140 \%$ del PIB para los países desarrollados, y entre la mitad y el $90 \%$ del producto para el caso de los países en desarrollo. Haciendo el supuesto de que la riqueza de una nación es aproximadamente tres veces su producto interno, (El supuesto se refiere a que el valor del acervo de capital representa comúnmente alrededor de tres veces el ingreso de un país.) es posible obtener una aproximación de la razón del valor de la vivienda residencial al total de la riqueza. Bajo este supuesto, las viviendas representan entre $30 \%$ y $40 \%$ del total de la riqueza para el grupo de países desarrollados y entre $15 \%$ y $30 \%$ para los países en desarrollo. (Estas estimaciones son semejantes a otras presentadas en la literatura. Por ejemplo, para el caso de México, Cervini (1995) estima que la vivienda representó en 1990 el 23\% del total del acervo de capital reproducible.) Es de hecho esta importancia relativa de la vivienda, en el total de la riqueza de una nación, el argumento más común para sostener la relevancia a nivel macroeconómico de los cambios en el sector de la vivienda.

b) El valor de la riqueza en vivienda es suficiente para permitir expansiones importantes del crédito hipotecario. La segunda columna del cuadro 1.1 es el resultado de restar del valor de las estructuras residenciales el monto del crédito hipotecario, o sea la riqueza neta en vivienda. En teoría, este valor representa la riqueza en vivienda que potencialmente podría servir como colateral 
y aún no ha sido utilizado. Específicamente, si se utilizara la cuarta parte del colateral disponible en los países en desarrollo, se incrementaría en más del 100\% el saldo del crédito hipotecario.

Es posible hacer un argumento similar al párrafo anterior pero utilizando al flujo de la inversión residencial en lugar del acervo. La inversión residencial bruta representa comúnmente alrededor de 4\% - 5\% del PIB. Para un país en desarrollo, financiar el total de esta nuevas construcciones significaría un aumento sustancial del crédito hipotecario. En el caso de los países desarrollados, es frecuente encontrar que casi toda la inversión residencial es financiada por los bancos e instituciones hipotecarias; inclusive el financiamiento hipotecario puede ser mayor a la inversión residencial por los créditos a estructuras ya existentes . (Comúnmente citado en la literatura como disminución del capital neto en vivienda (en inglés "net equity withdrawal"), ha sido un tema frecuente de estudio en el Reino Unido y otros países. Este comportamiento se vería reflejado en un aumento en los valores de la primera columna del cuadro 1.1 y una disminución en los de la segula segunda columna. Para el Reino Unido véase Miles(1994) y para un argumento similar en el caso de Finlandia véase Booth (1994).)

\section{Cuadro 1.1}

\section{Valor del Acervo de Vivienda y del Mercado Accionario}

valores de final del periodo como porcentajes del PIB

1990

\begin{tabular}{|c|c|c|c|c|c|c|c|}
\hline & $\begin{array}{l}\text { Acervo de } \\
\text { Vivienda }\end{array}$ & \begin{tabular}{|l} 
Riqueza \\
Neta en \\
Vivienda \\
$5 /$
\end{tabular} & $\begin{array}{c}\text { Valor del } \\
\text { Mercado } \\
\text { Accionario }\end{array}$ & & $\begin{array}{l}\text { Acervo de } \\
\text { Vivienda }\end{array}$ & $\begin{array}{l}\text { Riqueza } \\
\text { Neta en } \\
\text { Vivienda 5/ }\end{array}$ & $\begin{array}{l}\text { Valor del } \\
\text { Mercado } \\
\text { Accionario }\end{array}$ \\
\hline \multirow[t]{2}{*}{$\begin{array}{l}\text { Países } \\
\text { Desarroll } \\
\text { ados }\end{array}$} & & & & $\begin{array}{l}\text { Países en } \\
\text { Desarrollo }\end{array}$ & & & \\
\hline & & & & Asia & & & \\
\hline Grecia 1/ & 138.0 & 131.4 & 11.8 & Filipinas & 91.8 & & 13.0 \\
\hline $\begin{array}{l}\text { Finlandia } \\
\text { 2/ }\end{array}$ & 122.5 & 90.3 & 22.4 & Taiwan 3/ & 64.7 & & 98.0 \\
\hline $\begin{array}{l}\text { Reino } \\
\text { Unido }\end{array}$ & 106.0 & 52.5 & 87.0 & Corea & 61.6 & 42.8 & 45.1 \\
\hline Australia & 94.3 & 76.2 & 36.5 & $\begin{array}{l}\text { América } \\
\text { Latina }\end{array}$ & & & \\
\hline Noruega & 89.3 & 47.1 & 24.8 & Venezuela & 68.8 & 65.9 & 17.0 \\
\hline $\begin{array}{l}\text { Estados } \\
\text { Unidos }\end{array}$ & 86.8 & 33.8 & 55.7 & México & 68.3 & 65.7 & 13.5 \\
\hline
\end{tabular}




\begin{tabular}{|l|r|r|r|r|r|r|r|}
\hline España & 86.6 & & 32.2 & $\begin{array}{l}\text { Colombia } \\
4 /\end{array}$ & 46.9 & 41.5 & 3.4 \\
\hline & & & & & & & \\
\hline
\end{tabular}

Fuentes: Razones a PIB basadas en las siguientes Fuentes: Acervos de vivienda para países desarrollados (excepto España) tomados de OECD "Flows and Stocks of Fixed Capital. 1967-1992". Para España y países en desarrollo son estimaciones propias del autor, a excepción de Taiwan cuya fuente es "Statistical Yearbook of the Republic of China". Los porcentajes del valor del mercado accionario fueron calculados con base en cifras en dólares de IFC "Emerging Stock Market Factbook 1996" y divididas por el PIB en Dólares.

Notas: 1/ Información para 1989.

2/ Información para 1988.

3/ Información para 1988. El acervo de vivienda incluye construcciones adyacentes a la vivienda.

4/ Incluye sólo la bolsa de Bogotá.

5/ Riqueza neta en vivienda construida restando al valor del acervo de vivienda el valor de los créditos hipotecarios

c) La desregulación financiera fue condición necesaria pero no suficiente para las expansiones observadas en el crédito hipotecario ya que éstas fueron financiadas utilizando recursos del exterior. Durante 1985-1995 existieron en diversos países expansiones sustanciales del crédito hipotecario, señalándose a un proceso de desregulación financiera como la causa. No obstante, a la par de las expansiones crediticias se dio una disminución en el ahorro interno. Si bien la liberalización financiera permitió el incremento del crédito al sector vivienda, esto no hubiera sido posible sin la utilización de recursos del exterior. (Este punto es el argumento central en Guerra (1997).)

En la literatura generalmente se modela al proceso de desregulación financiera como la anulación de restricciones crediticias. Sin embargo, las restricciones que se utilizan para modelar, como la razón de crédito a valor de la casa, tienen un comportamiento cíclico. Este comportamiento contradice la idea de que se trata de restricciones puramente legales. Una hipótesis alternativa sería que la menor injerencia del gobierno en el proceso de otorgamiento de crédito y la derogación de barreras a la entrada, permitió una competencia mayor entre las distintas instituciones financieras. Si los bancos encuentran la posibilidad de captar recursos del exterior a una tasa relativamente pequeña, un enorme mercado a donde pueden dirigir estos recursos es el hipotecario. Un efecto natural de este proceso es que los intermediarios financieros reduzcan los requisitos de otorgamiento de crédito con la finalidad de ganar una mayor parte del mercado. Basta revisar el comportamiento del enganche requerido, como porcentaje del valor de la casa, para constatar que estas restricciones también tienen un comportamiento ligado al ciclo inmobiliario.

d) Los precios de las casas generalmente tienen un comportamiento cíclico. La evidencia empírica demuestra que no es raro encontrar episodios en donde existen importantes movimientos en el precio relativo de las casas, y en un período relativamente corto de tiempo. Es común que las bajas pronunciadas en el precio de los bienes raíces coincidan con crisis financieras.

La gráfica 1.1 presenta índices del precio real de las casas para un grupo de países desarrollados y en vías de desarrollo. La información difiere tanto en el período de tiempo analizado como en la definición básica de los conceptos. Algunos índices son construidos usando precios anunciados en los periódicos, otros usando índices de precios hedónicos, etc. En el caso de México se trata solamente de una aproximación que se construyó utilizando el componente de arriendo del Índice Nacional de Precios al Consumidor dividido por una tasa de descuento. 
Para los Estados Unidos, Reino Unido y Alemania se cuenta con una perspectiva de largo plazo. Existe una clara apreciación del precio real de las casas pero con un comportamiento cíclico. Por otra parte, los países asiáticos tuvieron una impresionante tendencia alcista en el precio de las casas durante los ochenta. El caso de Hong Kong es particularmente impresionante dado que se multiplicaron los precios de las casas por un factor de cuatro en menos de diez años.

Es interesante notar que para América Latina y los Países Nórdicos se observan ciclos relativamente pronunciados. En Finlandia, Chile y Uruguay los precios aumentaron en casi un 100\% y disminuyeron en una magnitud similar en tan sólo cinco años.

Finalmente, se puede afirmar que es posible encontrar episodios donde el colateral hipotecario, representado por el precio de una casa, puede ser erosionado en tan sólo unos años. Cambios tan drásticos en el precio los activos inmobiliarios pueden tener implicaciones macroeconómicas: basta comparar el peso relativo del mercado accionario con el de la vivienda (véase la tercer columna del cuadro 1.1), para entender la necesidad que existe de dar mayor relevancia al análisis de los bienes raíces. 


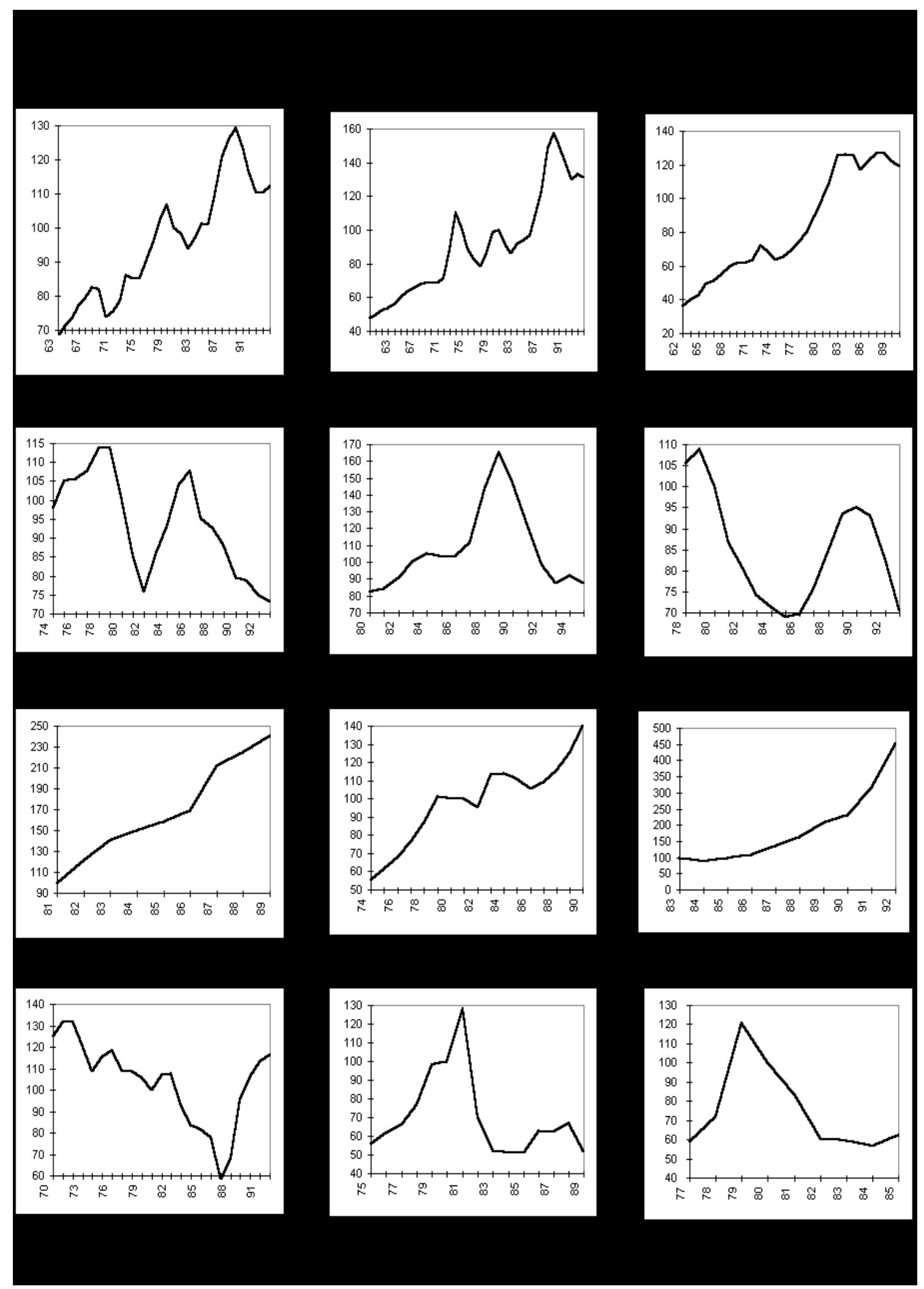

\section{La Hipoteca como una Opción de Venta.}

La cartera vencida de los bancos refleja la decisión de no pago de los individuos. De acuerdo con la literatura han existido básicamente dos teorías alternativas para explicar la moratoria. La primera, que se basa en el concepto del capital neto de la vivienda (valor de la casa menos crédito), presenta a los deudores como agentes racionales que evalúan los costos y beneficios financieros de seguir 
pagando su hipoteca. La segunda, sostiene que el deudor seguirá cubriendo su hipoteca mientras su ingreso sea suficiente para cumplir con los pagos.

Más de tres décadas de análisis teórico y resultados empíricos han señalado que el saldo del valor de mercado de la casa menos el monto del crédito es el principal determinante de la moratoria de la cartera hipotecaria. Así, la teoría que considera al deudor como un agente racional, predomina sobre aquélla que sólo incluye a los flujos corrientes del pago de la hipoteca. Por ejemplo, en una reseña de la literatura que analiza 29 estudios empíricos Quercia y Stegman (1992) encuentran que :

"En todos los casos, el valor neto de la vivienda, o una variable relacionada con la razón crédito a valor, se ha encontrado que influye en la decisión de suspensión de pagos" (Quercia y Stegman (1992) página 357. Traducción del autor.)

La literatura más reciente sobre la decisión de moratoria ha evolucionado hacia la teoría de opciones para modelar la decisión de pago de una hipoteca. Este enfoque hace énfasis en las características del crédito y no del acreditado, relegando el papel de variables como el ingreso del deudor a un segundo término.

Un deudor siempre tiene la opción de dejar de pagar su hipoteca con lo cual le regresaría la casa al banco. Esta operación es equivalente a vender la casa en el mercado a un monto igual al de la hipoteca. Es decir, el deudor siempre tiene una opción de venta con un precio de ejercicio igual al monto del crédito. Cuando el precio de mercado de la casa es inferior al monto del crédito, al deudor le conviene ejercer su opción declarándose en moratoria. Es entonces que el deudor "vende" (regresa) la casa al banco al valor del crédito. (A una hipoteca con una tasa fija se le puede concebir como la combinación de una opción de venta y una opción de compra. Esta última se refiere al derecho que un deudor tiene de refinanciar su hipoteca cuando la tasa de interés baja, el llamado derecho de prepago. Para el caso de la cartera vencida en México, la parte correspondiente a la opción de venta, es de mayor interés para el sistema financiero. No obstante, los créditos reestructurados en UDIS a una tasa fija en términos reales, se pueden enfrentar a un riesgo de prepago. Si la tasa de interés real para una hipoteca baja, por ejemplo, de $9 \%$ a $6 \%$ puede existir un proceso de refinanciamiento hipotecario como es frecuente encontrar en otros países.)

La teoría de opciones en su forma más simple tiene fuertes implicaciones sobre el problema hipotecario:

- Sólo aquellos créditos cuyo saldo supera al valor de la casa serán los que se declaren en suspensión de pagos.

- Un deudor que tiene problemas de liquidez para enfrentar los pagos de su hipoteca puede tratar de evitar la moratoria definitiva al vender su casa y pagar al banco. Si la casa vale menos que el adeudo hipotecario, el deudor puede estar reacio a enfrentar una pérdida de capital y por lo tanto entraría en moratoria. Por otra parte, si la casa vale más que el crédito el deudor puede pagar al banco evitando la moratoria.

- En principio, un deudor que enfrenta problemas de liquidez podría resolverlos con un refinanciamiento a un plazo mayor. Por lo mismo, un comportamiento diferenciado entre deudores debería ser explicado por el monto del capital neto en vivienda.

Existe en la actualidad una controversia teórica sobre si el deudor ejercerá su opción de venta de forma automática cuando se encuentre "dentro del dinero", es decir cuando 
donde C es el valor del crédito y V el valor de la vivienda. (Véase por ejemplo el artículo de Deng, Quigley y Van Order (1997).) Por otra parte, puede ser valioso para el deudor esperar cierto tiempo ya que hay costos de reputación y transacción cuando se ejerce la opción de no pago. Esto resultaría en que la opción no se ejercería automáticamente. Añadiendo a (1.1) los costos de ejercer la opción de venta (CE) entonces:

$$
\begin{aligned}
& \mathrm{C}>\mathrm{V}+\mathrm{CE} \\
& \mathrm{C}-\mathrm{V}>\mathrm{CE}
\end{aligned}
$$

Si el negativo del capital neto en vivienda es mayor a los costos de ejercicio (CE), la opción de venta será ejercida. Mientras más pequeños sean estos costos, mayor será la probabilidad de no pago. Así las cosas, la disputa actual no es tanto si el capital neto en vivienda (V-C) es el determinante principal de la decisión de moratoria; se trata de evaluar que tan importantes son los costos de transacción o de ejercicio, y de que forma afectan a la decisión del deudor.

En el caso de México, la existencia de un proceso legal de adjudicación del colateral, el cual es lento e incierto, añade valor a la opción de venta que detenta el deudor. Asimismo, la falta de un buró de información crediticia funcionando de manera generalizada reduce los costos de reputación que podría generar la moratoria. Por otra parte, los costos de transacción (gastos notariales e impuestos, depósitos de rentas) para comprar o rentar una casa nueva disminuyen el valor de la opción.

Estudios empíricos para los Estados Unidos han encontrado a la razón crédito a valor de vivienda positivamente relacionada con la probabilidad de no pago y estadísticamente significativa. Otras variables que son características del deudor como la relación pago de la hipoteca a ingreso, número de hijos, tipo de trabajo, etc. han sido encontradas significativas únicamente en algunos estudios. Lo anterior sugiere que en general las características de los deudores no serían relevantes. (Véase la cita hecha en la introducción al artículo de Kau, Keenan y Kim.) Esto último, en parte puede deberse a que es común contar con información sobre las características del deudor al principio del crédito, pero no a lo largo del tiempo; es decir, se sabe cuanto ganaba el deudor al tomar la hipoteca pero no se conoce cuál era su ingreso cuando se decidió por dejar de pagar.

En relación a la opción de venta de la hipoteca, hay que señalar que no existen instituciones que permitan a la sociedad en su conjunto, y en particular al sector financiero, asegurarse ante eventuales cambios en los precios de los bienes raíces. Aún con la bursatilización, el riesgo sólo se transfiere a los tenedores de los bonos respaldados con el bien raíz o a las finanzas públicas si el gobierno se encarga del riesgo de moratoria. Existe un riesgo sistémico sobre el cual, como sociedad, no tenemos la capacidad de cubrirnos o asegurarnos.

No existen instituciones que nos expidan una póliza ante cambios bruscos en el valor de nuestras casas, parte sustancial de nuestra riqueza. La formación de estas instituciones y mercados ha sido el tema del trabajo desarrollado por Robert J. Shiller y otros investigadores. (Véase Shiller, Robert J. (1993) "Macro Markets: Creating Institutions for Managing Society's Largest Economic Risks", Clarendon Press, Oxford.) Una de las tareas prioritarias, siguiendo la recomendación de estos autores, es el construir índices de precios de bienes raíces que permitan en un futuro la conformación de estos mercados. Se considera que para el caso de México este es un tema relevante. 


\section{La Hipoteca Mexicana con Tasa Dual.}

Lo que en esta sección se denomina "hipoteca de tasa dual" (la llamada hipoteca mexicana) se refiere a una serie de instrumentos de crédito a la vivienda utilizados en México. (Véase Barry et. al. (1995), Lea (1995), Maydon (1988) y Sánchez (1995), para una descripción de las características y orígenes de la hipoteca de índice dual.) En términos generales, estos instrumentos tenían por objetivo resolver el problema de la amortización real acelerada. Aunque los esquemas hipotecarios varían a lo largo del tiempo y entre las distintas instituciones financieras, todos tenían en común el permitir el refinanciamiento de intereses. Este refinanciamiento estaba dado por:

$$
\text { Refinanciamiento }=\left(\mathrm{C}_{\mathrm{t}}\right)\left(\mathrm{i}_{\mathrm{t}}\right)-\mathrm{P}_{\mathrm{t}}
$$

en donde $\mathrm{C}_{\mathrm{t}}$ se refiere al saldo del crédito hipotecario en el período $t, \mathrm{i}_{\mathrm{t}}$ la tasa de interés aplicable, $\mathrm{y}$ $\mathrm{P}_{\mathrm{t}}$ el pago en el período. De esta forma existiría refinanciamiento siempre que los intereses del período $\left\{\left(\mathrm{C}_{\mathrm{t}}\right)\left(\mathrm{i}_{\mathrm{t}}\right)\right\}$ eran superiores al pago $\left\{\mathrm{P}_{\mathrm{t}}\right\}$. Estos intereses no pagados eran capitalizados, aumentando el saldo del crédito hipotecario.

Se le denomina genéricamente hipoteca de tasa dual ya que se utilizaba un índice para el pago $\left\{\mathrm{P}_{\mathrm{t}}\right\}$ y otro para la tasa de interés $\left\{\mathrm{i}_{\mathrm{t}}\right\}$. Por ejemplo, el pago podría indizarse al salario mínimo y la tasa de interés a una canasta de tasas de corto plazo (la tasa más alta entre el CPP y CETES a 28 días). De esta forma, el refinanciamiento variaba dependiendo de las tasas de interés a corto plazo y la evolución del índice utilizado para el pago.

Si en algún mes el pago no cubría la totalidad de los intereses generados $\left\{\left(\mathrm{C}_{t}\right)\left(\mathrm{i}_{\mathrm{t}}\right)>\mathrm{P}_{\mathrm{t}}\right\}$ el banco refinancíaba la diferencia capitalizándola. No obstante, mientras el pago de la hipoteca sea igual o superior a la parte real de los intereses, entonces no se incrementaba en términos reales el saldo del crédito.

La hipoteca de índice dual tiene la desventaja potencial de incurrir en amortización negativa. Esto significa que el saldo del crédito hipotecario en términos reales se podría incrementar ya que el banco otorgaba financiamiento adicional al deudor. Esta era una decisión que no dependía de la institución financiera sino de las condiciones del mercado. En estos créditos, la variable de ajuste era el plazo de la hipoteca ya que generalmente se estipulaba la posibilidad de extenderlos. Otra posibilidad era establecer un tope máximo al saldo de la hipoteca a partir del cual se tendría que pagar la totalidad de los intereses.

En México gran parte de los créditos hipotecarios otorgados durante el período 1992-1994 incurrieron en amortización negativa en los primeros años. Esta experiencia contrasta con la de otros países donde los esquemas hipotecarios son tales, que el saldo real de la hipoteca siempre disminuye. A manera de ilustración, la gráfica 3.1 presenta una "hipoteca típica" (aquélla cuyo saldo siempre disminuye en términos reales) y la "hipoteca mexicana" (cuyo saldo en términos reales puede incrementarse). 


\section{GRÁFICA 3.1}

\section{EVOLUCIÓN DEL VALOR DE UNA HIPOTECA COMPARADO CON}

\section{EL PRECIO DE UNA CASA}

HIPOTECA TIPICA

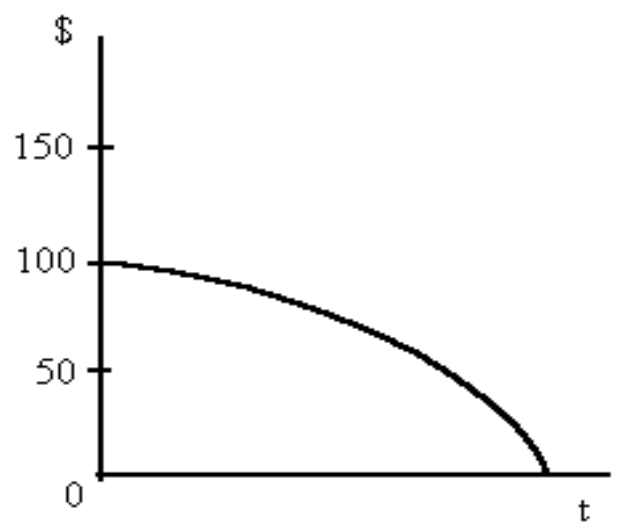

HIPOTECA TIPICA CON VALOR DE LA CASA CONSTANTE

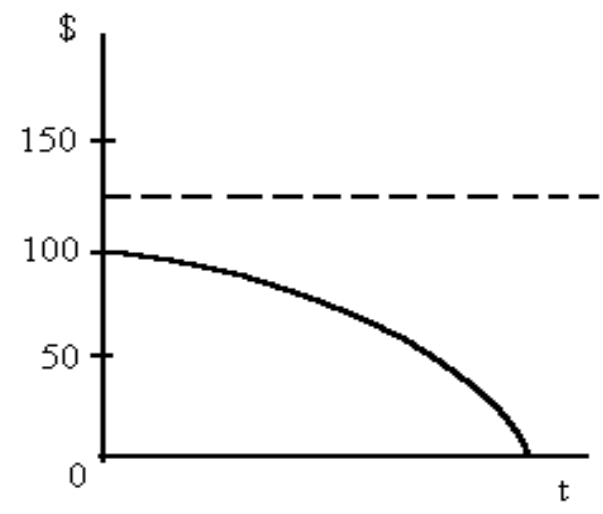

HIPOTECA MEXICANA INICLADA AL PRINCIPIO DEL CICLO

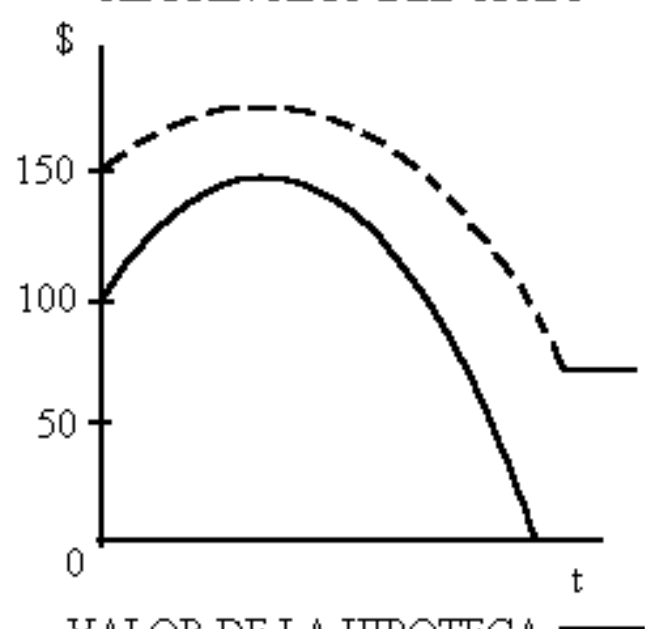

HIPOTECA MEXICANA

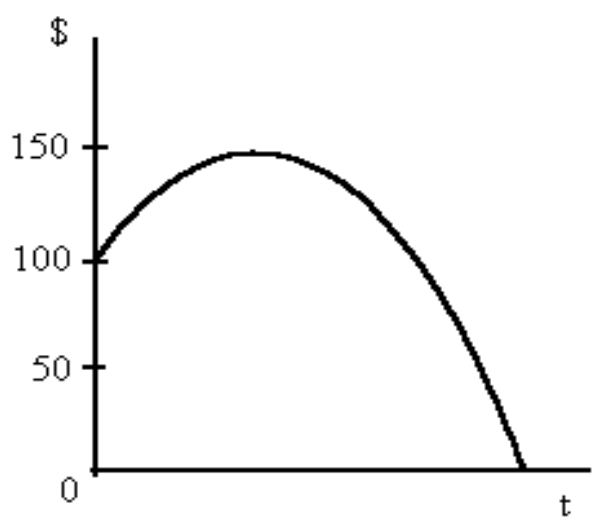

HIPOTECA MEXICANA CON VALOF

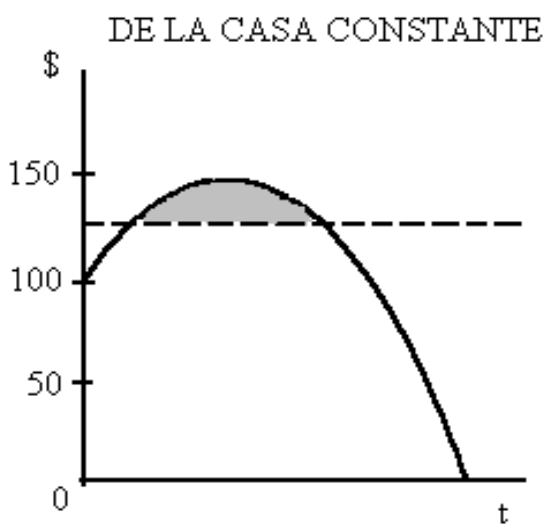

HIPOTECA MEXICANA INICLADA A LA MITAD DEL CICLO

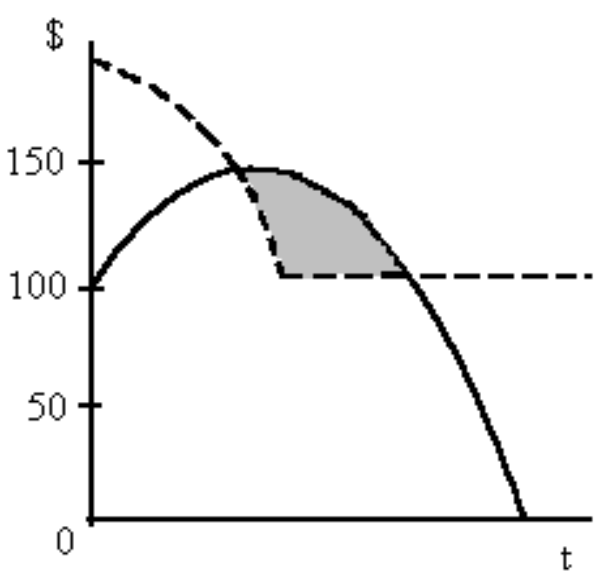

PRECIO DE LA CASA ---- 
Supóngase que se adquiere una casa a un precio de \$125 con un financiamiento por \$100. Si el precio de la casa se conserva constante (en términos reales), la hipoteca mexicana puede incurrir en capital neto negativo (área sombreada) pero no así la hipoteca típica. ¿Qué tan probable es que el saldo de la hipoteca mexicana rebase el valor de la casa? Dependerá de las particularidades del esquema crediticio. Un factor importante es el monto del capital neto inicial, es decir el porcentaje del enganche requerido. Dado un esquema crediticio, mientras mayor sea el enganche, menor será la probabilidad de incurrir en capital neto negativo.

Otro factor fundamental que determina la evolución del refinanciamiento es la tasa de interés real. No obstante que generalmente se fijaba una sobretasa (por ejemplo, siete puntos porcentuales sobre la tasa base), la tasa real variaba a lo largo del tiempo. Mientras mayor era la tasa de interés real, más grande era el refinanciamiento en términos reales y el consecuente incremento en el saldo hipotecario.

En la sección 1 se observó que los precios de las casas no se conservan constantes (véase gráfica 1.1) ya que tienen un comportamiento altamente cíclico. Esto significa que dependiendo de la parte del ciclo en que la hipoteca se inicie, la probabilidad de incurrir en capital neto negativo cambiará. Las dos gráficas inferiores presentan dos casos posibles: en uno la amortización del crédito coincide con el ciclo del precio de la casa; en el otro la hipoteca inicia cuando el precio de la casa baja. Lo que resta del documento trata de probar empíricamente que este último caso representa en gran parte lo ocurrido en México durante el período 1991-1994. A la par de un incremento en la hipoteca, los precios de los bienes raíces disminuyeron; el capital neto en vivienda se erosionó aumentando sustancialmente la probabilidad de una suspensión de pagos.

Por otra parte, hay que señalar que la hipoteca generalmente es considerada en otros países como un instrumento de ahorro. Esto no se puede afirmar de una hipoteca de tasa dual, ya que potencialmente es un instrumento que otorga financiamiento adicional. El monto del refinanciamiento no depende de una decisión del deudor o del banco, sino de las condiciones del mercado. Asimismo, hay que señalar que el destino final de esta liquidez adicional puede ser el consumo. No queda claro que este sea un objetivo deseable para un esquema crediticio. (No se incluye en esta observación a los programas de vivienda social cuyos objetivos pueden ser guiados por otros criterios.)

Finalmente, es posible argumentar que la amortización negativa es poco probable. No obstante, en períodos de expansiones del crédito hipotecario, la competencia por ganar participación en el mercado hipotecario hace que la amortización negativa sea el evento más factible. Es común encontrar episodios en donde, a la par de la expansión crediticia, los requisitos para los créditos hipotecarios disminuyen. México no ha sido la excepción, durante 1989-1994 los bancos compitieron disminuyendo los requisitos para obtener un crédito hipotecario, como el enganche y la mensualidad inicial. Adicionalmente, era de esperarse que para compensar el riesgo crediticio que estos cambios representaban, se podría incrementar la sobretasa de interés. Todo esto se traducía en un aumento en el refinanciamiento y en la probabilidad de incurrir en amortización negativa.

\section{4.- La Determinación del Alquiler en México: una Visión Macroeconómica.}

Antes de proseguir con el análisis de la cartera vencida hipotecaria es necesario investigar los determinantes de los precios de los bienes raíces. Si se considera al precio relativo del arriendo 
como indicativo de las condiciones del mercado inmobiliario, se podría esperar que los precios de los bienes raíces reaccionen a estas condiciones o fundamentos. Por ejemplo, así como el precio de las acciones es una función de los dividendos esperados, los precios de las casas pueden ser una función de las condiciones esperadas en el mercado inmobiliario, es decir una función de las rentas. En la siguiente sección se comprobará que el comportamiento cíclico de los precios de los bienes raíces está relacionado con los arriendos. Considerando lo anterior, se analizan los factores que determinan las rentas.

Antes de analizar la determinación del alquiler en México, resulta conveniente revisar cuál ha sido su comportamiento a través del tiempo. En la gráfica 4.1 puede apreciarse que a lo largo de los años setenta el precio real de las rentas tuvo una tendencia negativa moderada. Desde 1982 esta tendencia se acentúa, alcanzando el precio relativo su punto más bajo en 1988. A partir de esta fecha, el índice se recuperó rápidamente, aumentando $140 \%$ en términos reales en tres años. En realidad este incremento fue la recuperación, durante un período de tiempo relativamente corto, de los niveles que tenía el índice al inicio de la década pasada.

\section{GRÁFICA 4.1}

\section{México: Índice Real de la Renta de Vivienda y Transferencia Neta de Recursos}

\section{(1970-1995)}

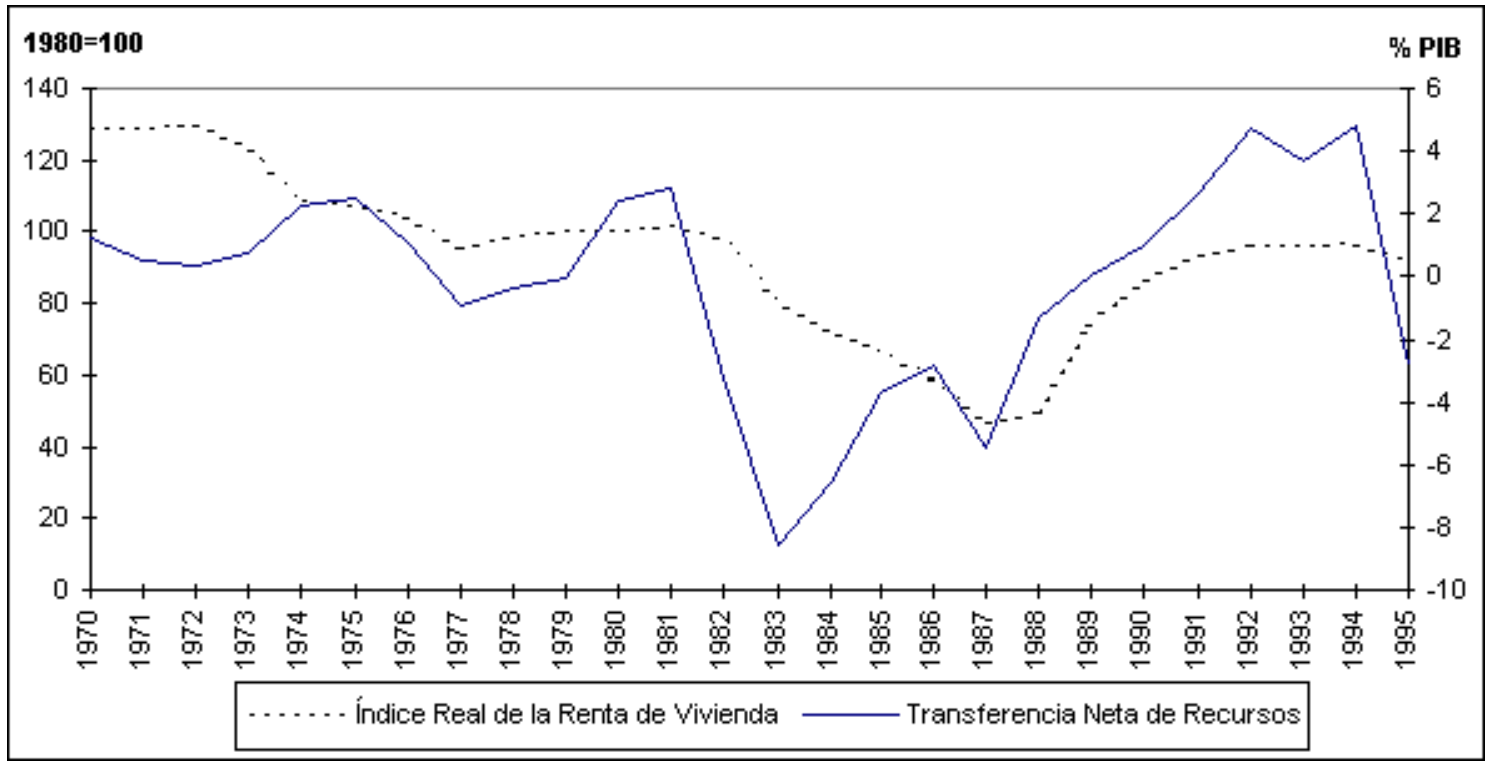

Distintas hipótesis han sido adelantadas para explicar el comportamiento del arriendo. El análisis se inicia en la sección 4.1, utilizando la teoría más tradicional de la determinación del arriendo. (Existen otros análisis relevantes para el caso mexicano como el de Murillo (1991), el cual para explicar la existencia de un ajuste parcial en el arriendo, hace referencia a la estructura contractual de los servicios de vivienda. Básicamente, se analiza el comportamiento inercial de las rentas aludiendo a una rigidez que "implica lentitud en la velocidad de ajuste de los alquileres y genera efectos inerciales en la formación de alquileres".) Una visión alternativa sobre la determinación del precio relativo de la rentas es la que se explora en la sección 4.2. Los servicios de vivienda, al igual que muchos otros servicios, tienen la característica de ser prestados por un acervo que no es movible: uno no puede exportar su casa, ni tampoco es común exportar, aunque es posible, a su peluquero. Son servicios no comerciables cuyo precio relativo debe ser afectado por cambios en la demanda, de una forma distinta a los bienes comerciables. Estos conceptos están más relacionados con la literatura sobre la determinación del tipo de cambio real y los flujos de capital, se trata de una visión macroeconómica. Sobre este enfoque se hará énfasis en el documento. 
4.1 La Demanda de Servicios de Vivienda: un Análisis Tradicional.

Como cualquier bien durable, en el caso de la vivienda la demanda fundamental es por el servicio que el acervo de vivienda presta. Esto lleva a diferenciar entre los siguientes objetos de estudio:

- la demanda por el servicio que otorga el acervo del bien durable.

- la demanda derivada por el acervo del bien durable.

El primero se refiere al mercado de servicios de vivienda, en donde el precio objeto de estudio es el arriendo o renta. El segundo es el mercado de los bienes raíces, en donde se determinan los precios de las casas. La distinción es importante ya que en la literatura empírica sobre el tema existe cierta confusión. (Por ejemplo, Hamilton (1991) critica algunos análisis de la demanda de vivienda por no tomar en cuenta que la demanda debería influenciar directamente el precio de la renta, no al precio del activo.) Esto se debe principalmente a que es común hacer el supuesto de que los servicios de vivienda son proporcionales, o numéricamente iguales, al acervo de vivienda. De esta forma, generalmente se define el flujo de servicios de vivienda $(h)$ como proporcional al acervo de vivienda $(h=\phi H)$; el acervo de vivienda $(H)$ es medido ya sea con el número de viviendas o con su valor estimado.

En el análisis desarrollado en Muth (1988) se deriva una función de demanda de servicios de vivienda para el propietario de una casa; esta resulta ser $h=h(R, y)$, donde $y$ es la variable de ingreso y $R$ es el costo de usuario (renta implícita). Esta última variable se define como $R=P(r+d+m-\Delta$ $p$ ), donde $P$ es el precio de la casa, $r$ la tasa de descuento, $d$ es la tasa de depreciación, $m$ es el costo de mantenimiento y $\Delta p$ es la tasa de incremento en el precio de las casas. (Modelos de optimización de tiempo continuo, como los desarrollados por Miles (1994) encuentran una expresión similar para el costo de usuario.) $R$ debe ser igual, sin distorsiones de mercado, al arriendo pagado por rentar una casa similar. (En esta especificación no se incluye una tasa de impuestos, variable que por lo general es considerada en el análisis.)

Por su parte la demanda por el acervo de vivienda se define como

$$
H=H(P,(r+d+m-\Delta p), y)(4.1)
$$

De esta forma, una variación en alguno de los componentes de $(r+d+m-\Delta p)$ debe interpretarse como un desplazamiento de la demanda por casas, pero no de arriendos. (Véase DiPasquale y Wheaton (1996) para un análisis sobre estos temas.)

Para el análisis empírico se utiliza la siguiente especificación lineal de la demanda de vivienda:

$$
H^{*} t=b_{0}+b_{1} R_{t}+b_{2} y p_{t}+\varepsilon_{t}
$$

La ecuación (4.2) representa la demanda por los servicios de vivienda, que el acervo de estructuras residenciales genera. Se hace el supuesto, común en la literatura, de que los servicios de vivienda $h$, son proporcionales al valor del acervo de vivienda, por lo tanto se sustituye a $h$ por $H$ en la ecuación (4.2). Es importante señalar que $H^{*}$ se refiere al nivel deseado de servicios de vivienda, y que su precio es $R$ (el costo de usuario o renta implícita) y no $P$ (el precio de la vivienda). Finalmente, de la especificación en (4.2) se esperaría que $b_{1}<0$ y $b_{2}>0$.

En la estimación empírica se utilizan datos anuales para el período 1970-1995. Esto se debe a que no se cuenta con la información necesaria para estimar el acervo de vivienda con una periodicidad 
menor al año, por lo tanto sólo se estima la relación de largo plazo entre el acervo de vivienda y sus determinantes principales.

El acervo de vivienda se refiere al valor, en términos reales, de las estructuras residenciales. Para construirlo, se utiliza información de formación bruta de capital fijo en construcción residencial, y no se incluye al valor de los terrenos. La tasa de renta implícita se aproxima con el componente del arriendo de casas del INPC, deflactado por el índice general de precios. En la siguiente sección, se podrá verificar que el componente de rentas de casas del INPC es un buen indicador del comportamiento de los precios de los bienes raíces en México. Finalmente, la variable de ingreso es una aproximación al ingreso permanente calculada como: $y p_{t}=3 / 6^{*} y d_{t}+2 / 6^{*} y d_{t-1}+1 / 6^{*} y d_{t-2}$, donde $y p$ es el ingreso permanente y $y d_{\mathrm{t}}$ se refiere al ingreso disponible en el período $\mathrm{t}$, es decir, un promedio ponderado que asigna mayor peso a las observaciones más recientes.

El cuadro 4.1 reporta los resultados de una estimación por mínimos cuadrados ordinarios de la demanda por servicios de vivienda especificada en la ecuación (4.2). Los datos están en logaritmos, de forma tal que es posible interpretar los coeficientes $b_{1}$ y $b_{2}$ como las elasticidades ingreso y precio, respectivamente. Los signos son los esperados, pero las elasticidades encontradas son muy bajas. (Análisis empíricos para otros países por lo general sitúan a la elasticidad ingreso cercana a la unidad y a la elasticidad precio como menor a la unidad pero mayor a 0.5 (valores absolutos).) Una razón para las elasticidades bajas puede ser la utilización de una variable de tendencia. Sin embargo, otras regresiones en donde es incluida una variable de población, o se especificaba la relación en términos per cápita, dan coeficientes similares a los que se presentan. En consecuencia, los resultados indican que la demanda de servicios de vivienda en México es relativamente inelástica y que es posible esperar, una vez tomado en cuenta el efecto del crecimiento en el ingreso permanente, que esta demanda se incremente a una tasa de $3.7 \%$ cada año.

\section{CUADRO 4.1}

Estimación de Demanda de Vivienda: Mínimos Cuadrados Ordinarios

$$
\log \left(H_{t}\right)=b_{0}+b_{1} \log \left(Y_{p t}\right)+b_{2} \log \left(R_{t}\right)+\text { Tendencia }+c_{q}
$$

\begin{tabular}{|c|c|c|c|}
\hline \multicolumn{4}{|c|}{ Variable dependiente: $\mathrm{H}_{\mathrm{t}}$ (Acervo de vivienda) } \\
\hline \multicolumn{4}{|c|}{ Muestra: 1973-1994 } \\
\hline \multicolumn{4}{|c|}{ Número de Observaciones: 22} \\
\hline Variable & Coeficiente & Error Estándar & Estadístico t \\
\hline Constante & 11.71147 & 0.235122 & 49.81022 \\
\hline $\log \left(Y_{p}\right)$ & 0.364131 & 0.030741 & 11.84504 \\
\hline $\log \left(R_{t}\right)$ & -0.065947 & 0.007599 & -8.678616 \\
\hline $\mathrm{T}$ & 0.037317 & 0.000889 & 41.98193 \\
\hline $\mathrm{R}$ cuadrada & 0.999484 & Media Var. Dep. & 14.92942 \\
\hline
\end{tabular}




\begin{tabular}{|l|l|l|c|}
\hline R Cuadrada ajustada & 0.999399 & Desv Est. Var. Dep. & 0.312375 \\
\hline Error Est. De la Reg. & 0.007661 & Suma Resid al Cuadrado & 0.001056 \\
\hline Durbin-Watson & 1.194215 & Estadístico F & 11633.00 \\
\hline
\end{tabular}

Un problema adicional en la regresión anterior es la posibilidad de que las variables que se utilizan no sean estacionarias, aun cuando se ha tomado en cuenta la existencia de una tendencia. De hecho existe evidencia de que el acervo de vivienda, el ingreso disponible y la variable de renta son integradas de orden uno [ I(1)]. (En el anexo estadístico se presentan los resultados de las pruebas de raíces unitarias (Prueba de Dickey-Fuller aumentada y prueba de Phillips-Perron), confirmándose que dichas variables no son estacionarias.) Sin embargo, existe la posibilidad de que las variables estén cointegradas: es decir que en el largo plazo exista una relación de equilibrio entre ellas. Si existe dicha relación de cointegración, los residuales de la ecuación estimada en el Cuadro 4.1 deben ser estacionarios; en el anexo estadístico se presenta evidencia de que sí lo son. Adicionalmente, el cuadro 4.2 reporta los resultados de la prueba de cointegración de Johansen y el correspondiente modelo de corrección de errores. Ambos resultados confirman dicha relación y la existencia de una demanda relativamente inelástica.

Hay que advertir que en el caso de la estimación con un modelo de corrección de errores, la variable de tendencia se vuelve una constante y es significativa. Los valores de los coeficientes de cointegración son similares a los encontrados por mínimos cuadrados ordinarios. El coeficiente de la brecha del valor observado al valor de equilibrio implica que el ajuste hacia el equilibrio se da en un $47 \%$ durante un año.

\section{CUADRO 4.2}

\section{Pruebas de Cointegración}

Variables $H_{t}, Y_{p t}, R_{t}$, Tendencia

\begin{tabular}{|c|c|c|c|c|}
\hline \multicolumn{5}{|c|}{ Prueba de Cointegración de Johansen } \\
\hline \multicolumn{5}{|c|}{ Variables: $H_{t}, Y_{p t}, R_{t}$, con supuesto de tendencia lineal } \\
\hline Eigenvalor & $\begin{array}{c}\text { Razón de } \\
\text { Verosimilitud }\end{array}$ & Valor Critico al $5 \%$ & $\begin{array}{l}\text { Valor } \\
\text { Critico } \\
\text { al } 1 \%\end{array}$ & $\begin{array}{c}\text { No. de Vectores } \\
\text { Hipotético }\end{array}$ \\
\hline 0.899766 & 73.68844 & 42.44 & 48.45 & Ninguno** \\
\hline 0.666016 & 27.68349 & 25.32 & 30.45 & Máximo $1 *$ \\
\hline 0.249872 & 5.750216 & 12.25 & 16.26 & Máximo $2 *$ \\
\hline
\end{tabular}


Coeficientes Cointegrados Normalizados:

\begin{tabular}{|c|c|c|c|c|c|c|}
\hline 1.000000 & $\begin{array}{c}\mathrm{R}_{\mathrm{t}} \\
0.031158 \\
(0.00586)\end{array}$ & \multicolumn{2}{|c|}{$\begin{array}{c}Y_{\mathrm{pt}} \\
-0.265906 \\
(0.01847)\end{array}$} & $\begin{array}{c}\text { Tendenc } \\
\text { ia } \\
- \\
0.03815 \\
0 \\
(0.0003 \\
4)\end{array}$ & \multicolumn{2}{|c|}{$\begin{array}{l}\text { Constante } \\
-12.31993\end{array}$} \\
\hline \multicolumn{7}{|c|}{ Modelo de Corrección de Errores: $\Delta H_{t}=A_{0}+A_{1} \Delta Y_{p t}+\beta_{2} \Delta R_{t}+A_{3}\left(b r e c h a_{t-1}\right)+\varepsilon_{t}$} \\
\hline \multicolumn{7}{|c|}{ Variable dependiente: $\Delta \mathrm{H}_{\mathrm{t}}$ (Cambio en Acervo de vivienda) } \\
\hline \multicolumn{7}{|c|}{ Muestra: 1974-1994 } \\
\hline \multicolumn{7}{|c|}{ Numero de Observaciones: 21} \\
\hline Variable & Coeficiente & \multicolumn{2}{|c|}{ Error Estándar } & $\begin{array}{c}\text { Estadíst } \\
\text { ico } t\end{array}$ & & \\
\hline Constante & 0.041800 & \multicolumn{2}{|c|}{0.002051} & $\begin{array}{c}20.3823 \\
8\end{array}$ & & \\
\hline$\Delta \mathrm{Y}_{\mathrm{pt}}$ & 0.229953 & \multicolumn{2}{|c|}{0.050995} & $\begin{array}{c}4.50928 \\
7\end{array}$ & & \\
\hline$\Delta \mathrm{R}_{\mathrm{t}}$ & -0.035895 & \multicolumn{2}{|c|}{0.011338} & $\begin{array}{c}- \\
3.16606 \\
5\end{array}$ & & \\
\hline$\Delta$ Brecha $_{\mathrm{t}-1}$ & -0.468733 & \multicolumn{2}{|c|}{0.183464} & $\begin{array}{c}- \\
2.55490 \\
2\end{array}$ & & \\
\hline \multicolumn{2}{|l|}{ R cuadrada } & 0.587923 & \multicolumn{2}{|c|}{ Media Var. Dep. } & & 0.049183 \\
\hline \multicolumn{2}{|c|}{ R Cuadrada ajustada } & 0.515204 & \multicolumn{3}{|c|}{ Desv Est. Var. Dep. } & 0.008317 \\
\hline \multicolumn{2}{|c|}{ Error Est. De la Reg. } & 0.005791 & $\begin{array}{l}\text { Sum: } \\
\text { Cuad }\end{array}$ & Resid & & 0.000570 \\
\hline \multicolumn{2}{|c|}{ Durbin-Watson } & 0.808961 & Estac & o F & & 8.084814 \\
\hline
\end{tabular}


4.2 La Determinación del Alquiler Utilizando Variables Macroeconómicas.

Adicional al enfoque más tradicional, presentado en la sección anterior, existe una visión de la determinación del precio relativo de los servicios de vivienda que hace énfasis en la relación entre los bienes comerciables y no comerciables. En esta sección se utiliza un modelo elaborado por Arnold C. Harberger (Véase Harberger (1988)). en donde se determina el precio de un bien no comerciable como función del ingreso, de la cantidad demandada y de los flujos de capital. El modelo es más general y especifica relaciones dinámicas entre las distintas variables. Aquí, sólo utilizaremos una ecuación. El modelo especifica, entre otras relaciones, la oferta y demanda por un bien no comerciable en los siguientes términos:

$$
H^{d}=a_{0}+a_{1}\left(p_{h}-p_{t}\right)+a_{2} y+a_{3} B(4.3)
$$

$H^{s}=b_{0}+b_{1}\left(p_{h}-w\right)(4.4)$

en donde:

$$
\begin{aligned}
& H^{d}=\text { demanda por el bien no comerciable } \\
& H^{s}=\text { oferta del bien no comerciable } \\
& \left(p_{h}-p_{t}\right)=\text { precio relativo del bien no comerciable con respecto al bien comerciable } \\
& y=\text { variable de ingreso } \\
& B=\text { préstamos del exterior } \\
& w=\text { variable de salario }
\end{aligned}
$$

La ecuación de demanda fue concebida para ser aplicada en un entorno macroeconómico en donde existen básicamente dos tipos de bienes: comerciables y no comerciables. Ya que los servicios de vivienda representan alrededor de una tercera parte de los bienes no comerciables se considera pertinente utilizar esta especificación.

Existe otra razón por la cual la ecuación de demanda (4.3) es útil para el caso de la vivienda. Los coeficientes $a_{2}$ y $a_{3}$ no tienen por que ser iguales. Es una regularidad empírica que una parte importante de los flujos de capitales son dirigidos al sector de bienes no comerciables. Estimaciones hechas por el autor sugieren que en el pico de las expansiones crediticias de principios de los años noventa en México, alrededor de una tercera parte de los flujos de capital fueron dirigidos al sector de vivienda a través del sistema financiero(Véase Guerra (1997).). El que $a_{2}$ y $a_{3}$ no sean iguales, significa que no hay por que esperar que los flujos de capitales se gasten como si fueran ingreso adicional. Inclusive $a_{3}$ no tiene que ser estable a lo largo del tiempo, es decir que no siempre se van a usar los recursos obtenidos del exterior de la misma forma. Véase Harberger (1994) para una discusión sobre el tema.

La gráfica 4.1, presentada al inicio de esta sección, da un ejemplo de la relación entre una medida de flujos de capital (la transferencia neta de recursos) y el precio relativo de los arriendos frente al INPC. La transferencia neta de recursos se define como el negativo del balance de la cuenta de bienes y servicios no factoriales. Esto representa los recursos que entran al país en su conjunto y que ejercen una presión sobre la demanda agregada y variables como el tipo de cambio real. De hecho es el ahorro externo o entrada neta de capitales. Se puede esperar que los flujos de capital van a tener un papel relevante en la determinación del precio de los servicios de vivienda, por ser este un bien no comerciable. 
Modificando la ecuación (4.3) para adecuarla al caso de los servicios de vivienda se obtiene la siguiente especificación:

$$
\operatorname{Ren}_{t} / I N P C_{t}=a_{0}+a_{l} H_{t} / P O B_{t}+a_{2} y p_{t} / P O B_{t}+a_{3} T N R_{t} / P I B_{t}(4.5)
$$

donde:

Ren/INPC $=$ es el componente del arriendo de viviendas del INPC deflactado por el propio INPC.

$H / P O B=$ el valor del acervo de las construcciones residenciales per cápita como un indicador de la cantidad de servicios de vivienda.

$y p / P O B=$ el ingreso permanente per cápita definido como $y p_{t}=3 / 6^{*} y d_{t}+2 / 6^{*} y d_{t-1}+1 / 6^{*} y d_{t-2}$ donde $y d$ es el ingreso disponible.

$T N R / P I B=$ la transferencia neta de recursos del exterior como porcentaje del producto.

En esta especificación, el indicador de rentas de vivienda para la economía en su conjunto es una función de la cantidad demandada, del ingreso y de los recursos provenientes del exterior. Es posible esperar que $a_{1}<0, a_{2}>0$ y $a_{3}>0$. El cuadro 4.3 presenta los resultados de la estimación por mínimos cuadrados ordinarios. Las variables están en logaritmos a excepción de la transferencia neta de recursos, de forma tal que podemos interpretar a los coeficientes como elasticidades o semielasticidades.

Los coeficientes estimados presentan el signo esperado. La elasticidad con respecto al ingreso es cercana a dos y la elasticidad con respecto a la cantidad es unitaria. El coeficiente de TNR/PIB indica que un aumento en la entrada de recursos del exterior equivalente a un punto porcentual del producto genera un incremento cercano al $4 \%$ en el índice real de las rentas, controlando por el efecto del aumento en el ingreso y la cantidad demandada.

Al igual que en el análisis anterior, existe evidencia de que las variables utilizadas en la estimación de (4.5) no son estacionarias (ver anexo estadístico) lo que arroja ciertas dudas sobre la interpretación de los resultados obtenidos por mínimos cuadrados ordinarios. Más aun, la única variable en donde las pruebas no son conclusivas es la entrada de capitales, resultado que podría esperarse dada la restricción presupuestal que el país enfrenta con respecto al exterior. Para probar que las variables están cointegradas se verifica que los residuales de la estimación de (4.5) son estacionarios. El anexo estadístico presenta las pruebas de raíces unitarias para estos residuales, indicando que hay evidencia de una posible cointegración entre las variables. El cuadro 4.4 presenta los resultados de la metodología de Johansen para hacer la prueba de cointegración, donde de nueva cuenta se confirma los resultados antes obtenidos. No obstante, los coeficientes de cointegración señalan en este caso elasticidades de ingreso y cantidad mayores a las estimadas por mínimos cuadrados ordinarios. Inclusive, la semielasticidad de las rentas con respecto a la entradas de recursos del exterior se incrementa del $4 \%$ al 13\%. En suma, el análisis econométrico señala una relación de largo plazo entre el precio relativo del arriendo, el ingreso y la cantidad demandada, en donde también juegan un papel importante los recursos provenientes del exterior. 


\section{CUADRO 4.3}

Estimación de la Renta de Vivienda: Mínimos Cuadrados Ordinarios

$\log \left(\operatorname{Ren} n_{t} / I N C P_{t}\right)=a_{0}+a_{1} \log \left(H_{t} / P O B_{t}\right)+a_{2} \log \left(Y_{p t} / P O B_{t}\right)+a_{3} T M R_{t} / P I B_{t}$

Variable dependiente: $\log \left(\operatorname{Ren}_{\mathrm{t}} / \mathrm{INPC}_{\mathrm{t}}\right)$

Muestra: 1973-1994

Numero de Observaciones: 22

\begin{tabular}{|c|c|c|c|}
\hline Variable & Coeficiente & Error Estándar & Estadístico t \\
\hline Constante & 7.249845 & 2.992430 & 2.422728 \\
\hline $\log \left(\mathrm{H}_{\mathrm{t}} / \mathrm{POB}_{\mathrm{t}}\right)$ & -1.001640 & 0.212324 & -4.717503 \\
\hline $\log \left(\mathrm{Y}_{\mathrm{pt}} / \mathrm{POB}_{\mathrm{t}}\right)$ & 1.978817 & 0.689241 & 2.871009 \\
\hline $\mathrm{TNR}_{\mathrm{t}} / \mathrm{PIB}_{\mathrm{t}}$ & 0.038711 & 0.009138 & 4.236389 \\
\hline & & & \\
\hline R cuadrada & 0.717056 & Media Var. Dep. & 4.459291 \\
\hline R Cuadrada ajustada & 0.669899 & Desv Est. Var. Dep. & 0.257436 \\
\hline Error Est. De la Reg. & 0.147908 & Suma Resid al Cuadrado & 0.393782 \\
\hline Durbin-Watson & 0.904115 & Estadístico F & 15.20564 \\
\hline
\end{tabular}




\section{CUADRO 4.4}

\section{Pruebas de Cointegración}

Variables $\log ($ Ren/inpct), $\log$ (Ht/POBt), $\log$ (Ypt/POBt), TNR/PIBt

\begin{tabular}{|c|c|c|c|c|}
\hline \multicolumn{5}{|c|}{ Prueba de Cointegración de Johansen } \\
\hline \multicolumn{4}{|c|}{ Variables: $\log \left(\operatorname{Ren}_{t} / \mathrm{INPC}_{\mathrm{t}}\right), \log (\mathrm{Ht} / \mathrm{POBt}), \log (\mathrm{Ypt} / \mathrm{POBt}), \mathrm{TNR}_{\mathrm{t}} / \mathrm{PIBt}$} & \\
\hline Eigenvalor & $\begin{array}{c}\text { Razón de } \\
\text { Verosimilitud }\end{array}$ & Valor Critico al $5 \%$ & $\begin{array}{c}\text { Valor Critico al } 1 \\
\%\end{array}$ & $\begin{array}{c}\text { No. de } \\
\text { Vectores } \\
\text { Hipotético }\end{array}$ \\
\hline 0.756096 & 66.61315 & 53.12 & 60.16 & Ninguno** \\
\hline 0.622635 & 36.98258 & 34.91 & 41.07 & Máximo $1^{*}$ \\
\hline 0.371409 & 16.51717 & 19.96 & 24.60 & Máximo 2 \\
\hline 0.275489 & 6.767411 & 9.24 & 12.97 & Máximo 3 \\
\hline \multicolumn{5}{|c|}{$*(* *)$ Significa rechazo de la hipótesis al $5 \%(1 \%)$ de nivel de significancia. } \\
\hline \multicolumn{5}{|c|}{ Coeficientes Cointegrados Normalizados: 1 Ecuación de Cointegración } \\
\hline $\log \left(\operatorname{Ren}_{t} / \mathrm{INPC}_{\mathrm{t}}\right)$ & $\log (\mathrm{Ht} / \mathrm{POBt})$ & $\log (\mathrm{Ypt} / \mathrm{POBt})$ & $\mathrm{TNR}_{\mathrm{t}} / \mathrm{PIBt}$ & Constante \\
\hline \multirow[t]{2}{*}{1.000000} & 3.104720 & -2.682730 & -0.1298818 & -27.47792 \\
\hline & $(0.65735)$ & $(0.82144)$ & $(0.02980)$ & $(6.45185)$ \\
\hline
\end{tabular}

\section{5.- La Evolución del Precio de los Terrenos Urbanos en México.}

Es posible afirmar, basados en evidencia empírica de otros países, que el precio de los terrenos urbanos tiene un comportamiento similar al de las casas pero con ciclos más pronunciados (véase gráfica 5.1). No se cuenta con una serie histórica de precios de vivienda; sin embargo, el Banco de México ha construido un índice de precios de terrenos urbanos para la ciudad de México. En esta sección se presenta un análisis de la dinámica del precio de la tierra urbana con el objeto de investigar los determinantes de los precios de los bienes raíces en general. 
Es de esperarse que al graficar el precio de un activo a lo largo del tiempo, este se presente con pequeños brincos o movimientos aleatorios. No obstante que pueda existir por largos períodos una tendencia clara, es frecuente encontrar que mes a mes, o día a día, se registren cambios que no son del todo predecibles. En la gráfica 5.2 se presenta el índice de precios y cotizaciones de la Bolsa Mexicana de Valores deflactada por el INPC para el período de enero de 1980 a diciembre de 1996. Las variaciones en el índice no pueden ser proyectadas fácilmente ya que no existe gran correlación entre los cambios. En el análisis hecho en Shiller (1993), se señala que esta característica de las series de los precios de los activos no se presenta en los bienes raíces. En la gráfica 5.3 es posible analizar la evolución de un índice de precios de terrenos urbanos y del componente de rentas de vivienda del índice de precios al consumidor; ambas series se refieren a la Ciudad de México y están deflactadas. El precio de los terrenos urbanos se comporta de una forma más suave comparada con el índice de las acciones, al no presentar esas pequeñas variaciones que son características de precios de otros activos. (En el análisis hecho por Robert J. Shiller (1993) se señala que evidencia empírica de varios países confirma que los precios de los bienes raíces se comportan con una tendencia mucho más suave y que esta característica no se deriva de la metodología utilizada para construir los índices de precios.)

Las diferencias entre la dinámica del precio de las acciones y el precio de los terrenos puede ser explicada por los distintos grados de liquidez que existen en ambos mercados. En México, los costos de transacción de un bien raíz por lo general son del orden del 6\% al 8\% del precio de la casa o terreno. Por otra parte, una tendencia como la observada en los precios de los bienes raíces durante largos períodos de tiempo, no podría persistir en mercados muy líquidos ya que existirían grandes incentivos para la entrada de especuladores.

Los precios de los terrenos urbanos en la Ciudad de México han tenido a lo largo del tiempo un claro comportamiento cíclico con períodos de relativa estabilidad, aumentos y disminuciones importantes. El último episodio fue un incremento importante de su nivel más bajo en las últimas dos décadas a valores similares a los de principio de los años ochenta: el precio real de los terrenos aumentó por un factor de cuatro en un período de cuatro años. 

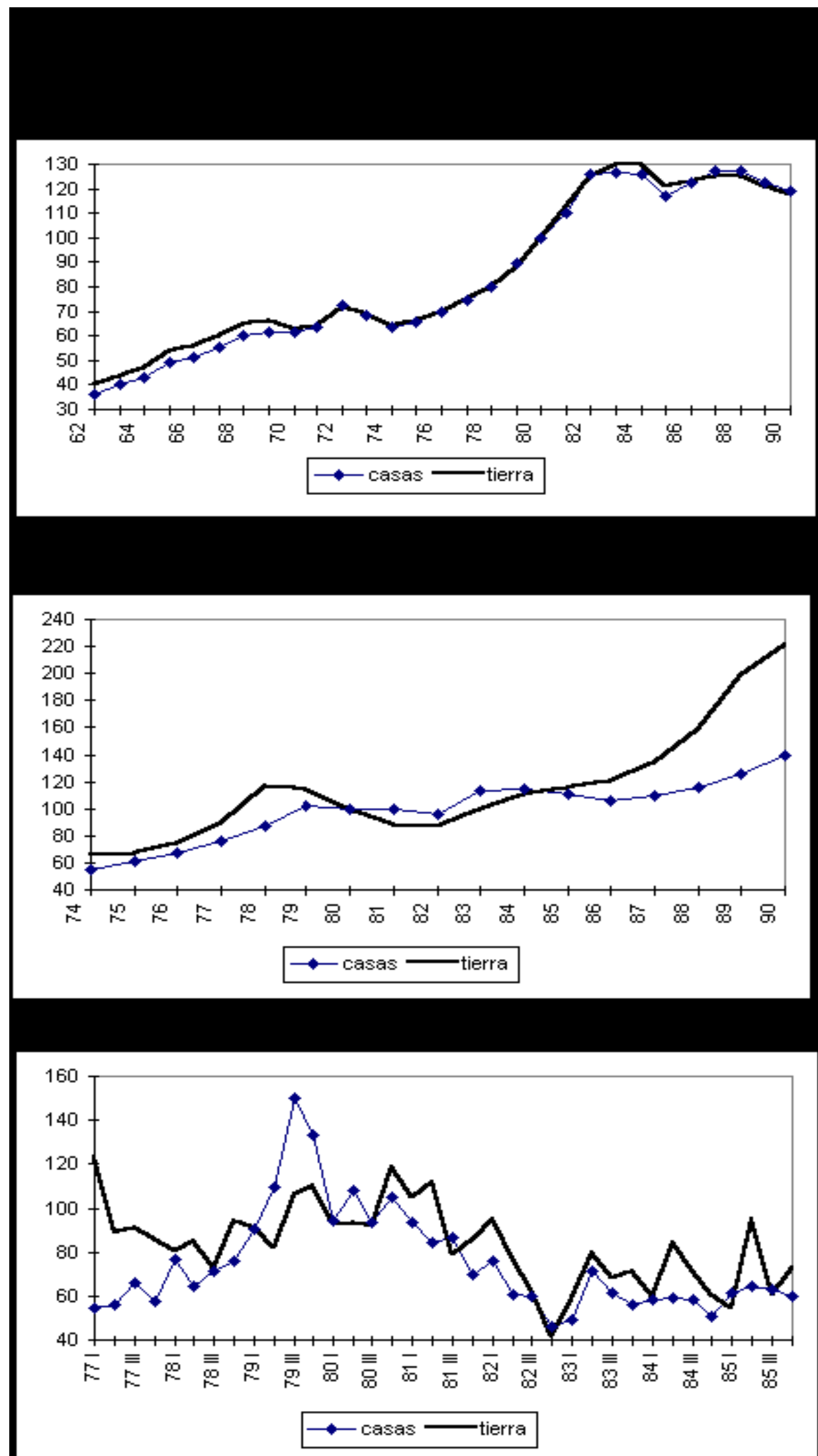

En la gráfica 5.3 se presenta también el índice de precios del alquiler en la Ciudad de México. Es posible observar que ambas series conservan la misma tendencia de largo plazo, pero con la serie de terrenos teniendo ciclos más pronunciados. Una posible explicación para este comportamiento sería que los precios de los terrenos responden a los mismos determinantes del arriendo de vivienda 
analizados en la sección pasada, no obstante existen otras hipótesis posibles.

GRÁFICA 5.2

Índice Real de Precios y Cotizaciones de la Bolsa Mexicana de Valores

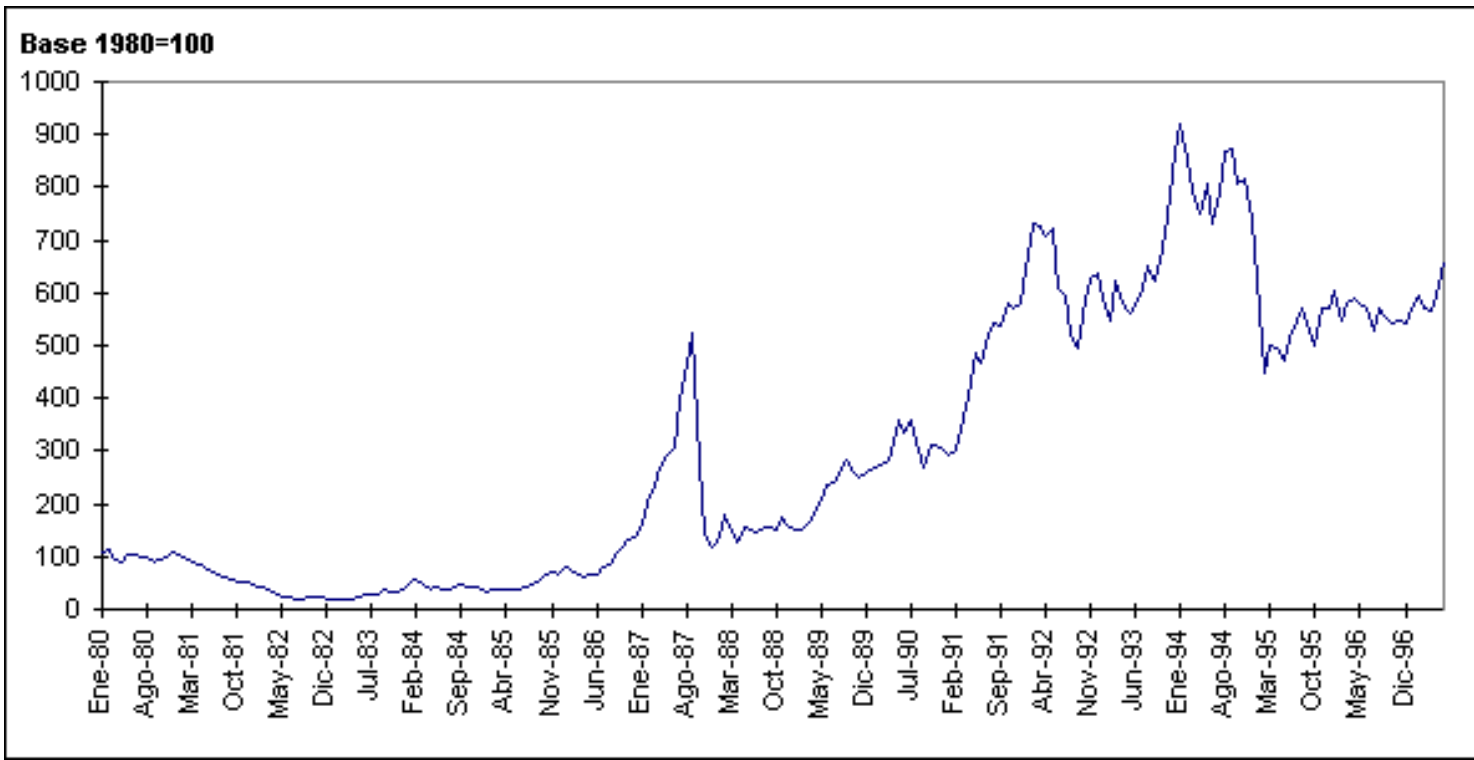

Los terrenos urbanos son activos cuyo precio debería ser una función de los rendimientos esperados en el futuro. Una variable que podría dar indicio de estos ingresos futuros es el nivel de las rentas. Esta relación entre el precio del activo y sus rendimientos esperados no necesariamente tiene que ser una relación lineal. Por ejemplo, en la literatura sobre la determinación del precio de las acciones se han desarrollado modelos donde existe una relación no lineal entre el precio del activo y los dividendos esperados. Los precios son sensibles a cambios en los dividendos y si estos se mantienen altos generan un incremento sustancial o "burbuja". Estas últimas, se definen como una desviación del precio del activo con respecto al valor presente de los flujos esperados de rendimientos en el futuro. En conclusión, se plantea la existencia de una relación no lineal entre el precio del activo y sus fundamentos.

El justificar una probable relación no lineal entre las rentas (fundamentos) y los precios de los terrenos (precio del activo), no será tema cubierto en el presente análisis. En los párrafos siguientes solamente se presenta evidencia sobre esta posible relación, dejando el análisis teórico y su comprobación empírica para otra investigación futura. 


\section{GRÁFICA 5.3}

\section{Precio Real de la Tierra Urbana y Alquiler Real}

(Cuidad de México)

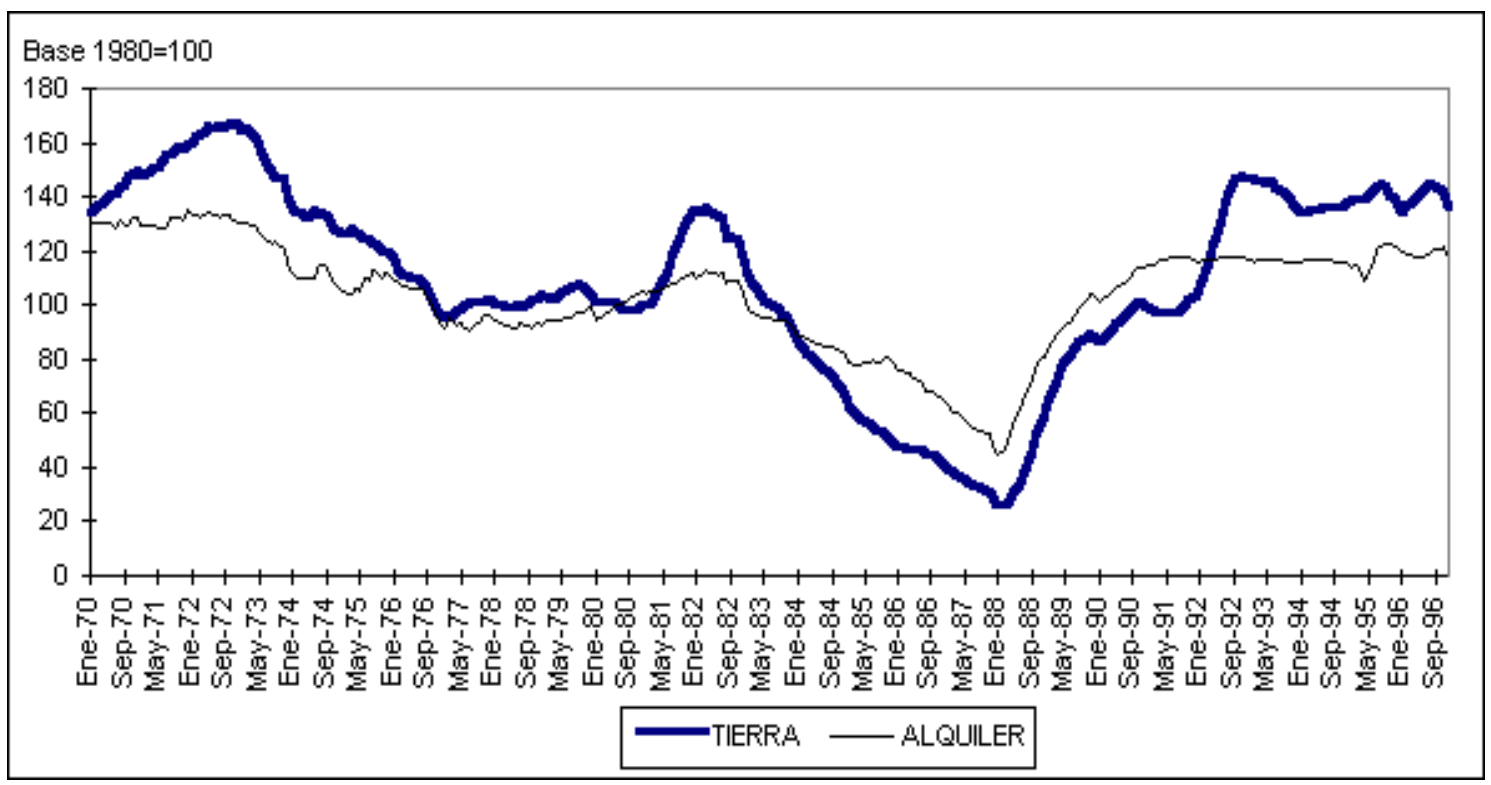

Existe evidencia de que las series presentadas en la gráfica 5.3 no son estacionarias. (Véase el anexo estadístico.) No obstante, utilizando pruebas econométricas de causalidad sobre las diferencias de las series (las cuales si son estacionarias), es posible afirmar que las rentas causan al precio de los terrenos en el sentido de Granger. (Para una descripción de las pruebas de causalidad de Granger y su significado véase Green (1993), página 553. En el anexo estadístico se presentan los resultados de las pruebas de causalidad de Granger utilizando las primeras diferencias en las series.) Es decir, los terrenos reaccionan a los cambios en el arriendo y no al revés.

En el modelo simple de valor presente, bajo el supuesto de expectativas racionales, el precio de un activo es proporcional al valor de los dividendos. De lo anterior se desprende que la razón del precio de los terrenos al índice de arriendos de casas debería ser más o menos constante. (Estadísticamente esto se traduciría en que la razón de las dos variables fuese estacionaria. En el anexo estadístico se presentan las pruebas de raíces unitarias para la razón y la diferencia de los logaritmos donde se concluye que no es estacionaria.) Una forma de comprobar que no se cumple la relación más simple del modelo del valor presente, es utilizando una regresión en logaritmos de Pt (precio de los terrenos) en función de una constante y de Dt (arriendo de casas). Si el precio de los terrenos es proporcional a la renta de vivienda, se debe obtener una elasticidad unitaria entre ambas variables. (En lo que sigue se utiliza la metodología descrita en Frooty Obstfeld (1991).)

En el cuadro 5.1 se presentan los resultados de la regresión descrita en el párrafo anterior. Si la elasticidad entre las variables fuese unitaria, entonces se debería obtener un coeficiente $\beta$ cercano a uno. El coeficiente estimado está entre el rango 1.8-2.0, (El valor de 2.0 se refiere al recíproco del coeficiente $\beta$ de la segunda regresión.) de donde se deduce que es probable que los precios de los terrenos son más sensibles a las rentas de lo que un modelo de valor presente predeciría. Estos resultados son cualitativamente similares a los obtenidos en el caso de las acciones y dividendos. 


\section{Cuadro 5.1}

\section{Relación entre el Precio Real de los Terrenos Urbanos y el Arriendo Real}

\begin{tabular}{|c|c|c|c|c|}
\hline & Ecuación & $\beta$ & $\mathrm{R} 2$ & $\mathrm{DW}$ \\
\hline 1 & $\mathrm{pt}=\alpha+\boldsymbol{\beta} \mathrm{dt}+\mathrm{v} \mathrm{t}$ & 1.84 & 0.92 & 0.16 \\
\hline 2 & $\mathrm{dt}=\alpha+\beta \mathrm{pt}+\mathrm{v} \mathrm{t}$ & 0.50 & 0.92 & 0.17 \\
\hline
\end{tabular}

De lo anterior sólo es posible concluir que los precios de los bienes raíces probablemente guardan una relación no lineal con respecto a sus fundamentos, en este caso representados por las rentas. Cabe recordar que en la sección anterior se encontró evidencia que las rentas respondían a variables macroeconómicas, como el ingreso y los flujos de capitales. Un cambio en estas últimas variables puede verse traducido en un efecto importante sobre el mercado de bienes raíces. Si el precio relativo del arriendo se incrementa por una fuerte entrada de capitales, se podría esperar que el efectos sobre el precio de los terrenos y casas sea aún mayor. En la siguiente sección se confirmará que este comportamiento cíclico del precio de los bienes raíces es relevante para la estabilidad del sistema financiero.

\section{6.- El Problema de la Cartera Hipotecaria en México.}

En esta sección se analiza la cartera vencida hipotecaria bajo el supuesto de que el valor de mercado de la casa menos el monto del crédito (el capital neto en vivienda), es el principal determinante de la decisión de pago de la hipoteca. Este supuesto implicaría que conforme el capital neto de la vivienda se hace negativo, la probabilidad de que no se pague la hipoteca aumentará. La sección inicia presentando un análisis sobre la tasa de retorno de un bien raíz comprado con una hipoteca, haciendo énfasis en el papel jugado por la relación inicial de valor del bien raíz a monto del crédito. Se continua con una estimación de la probabilidad de no pago, comparando su evolución con el porcentaje de cartera vencida observado. Finalmente, se explora la importancia relativa de la fecha de concesión de un crédito para explicar la probabilidad de moratoria. 
6.1 La Tasa de Rendimiento de un Bien Raíz Comprado con una Hipoteca.

Cuando se compra un bien raíz con una hipoteca el deudor puede elegir, dentro de ciertos rangos, el capital neto a invertir, es decir el monto del enganche. La tasa de rendimiento que el nuevo propietario del inmueble obtiene debe medirse sobre el monto adelantado y no sobre el valor total del bien raíz. Esta idea se sintetiza en el análisis hecho por Muellbauer y Murphy (1996) donde se define a la tasa de rendimiento como:

Tasa de rendimiento $=$

(\% Apreciación de capital + \% renta imputada neta -costo financiero)/ capital neto (6.1)

La ganancia de capital se refiere a cambios en el valor de mercado de la casa. La renta imputada neta es el ahorro generado por el propietario de la vivienda al no tener que pagar una renta, neta de los gastos de mantenimiento. El costo financiero son los intereses que genera la hipoteca. El capital neto invertido es el monto del enganche, incluyendo los costos de transacción para adquirir la vivienda.

Los elementos de (6.1) son expresados como porcentajes del precio del bien raíz, de tal manera que el costo financiero $=\mathrm{C} / \mathrm{V} * \mathrm{r}$, y el capital neto $=(1-\mathrm{C} / \mathrm{V}-\mathrm{CT})$, donde $\mathrm{C} / \mathrm{V}$ es la razón de crédito a valor del bien raíz, $\mathrm{r}$ es la tasa de interés y CT son los costos de transacción (gastos notariales e impuestos) como porcentaje del valor de la casa.

En la gráfica 6.1 se presenta una estimación de la ecuación (6.1), para el período 1990-1996, bajo los siguientes supuestos:

- la renta imputada representa $1 \%$ mensual del valor de la casa,

- los costos de transacción (notario, impuestos, etc.) son del 6\% del valor de la casa,

- la tasa de interés es la de CETES a 91 días + 7 puntos porcentuales,

- y finalmente, la ganancia de capital es calculada utilizando un índice de precios de terrenos urbanos de la Ciudad de México.

La tasa de rendimiento se calcula en términos reales deflactando, cuando corresponde hacerlo, por el INPC. Se hacen tres distintos supuestos sobre la razón inicial de crédito a valor del bien raíz (C/V): 0.7, 0.8 y 0.9, es decir enganches del 30\%, $20 \%$ y $10 \%$ del valor del terreno respectivamente.

La tasa de rendimiento fue positiva para un poco más de la mitad de los trimestres durante el período 1990-1996. El alto rendimiento durante 1991-1992 es producto de la rápida apreciación de los terrenos aunado a las tasas reales de interés descendentes. En contraste, durante el período 19931994 las tasas de rendimiento reflejan tanto la baja en el precio de los terrenos como el alza en las tasas de interés. 


\section{GRÁFICA 6.1}

\section{Tasa de Rendimiento Real de un Bien Raíz Comprado con una Hipoteca Bajo Distintos Supuestos de la Razón Inicial de Crédito/Valor del Bien Raíz}

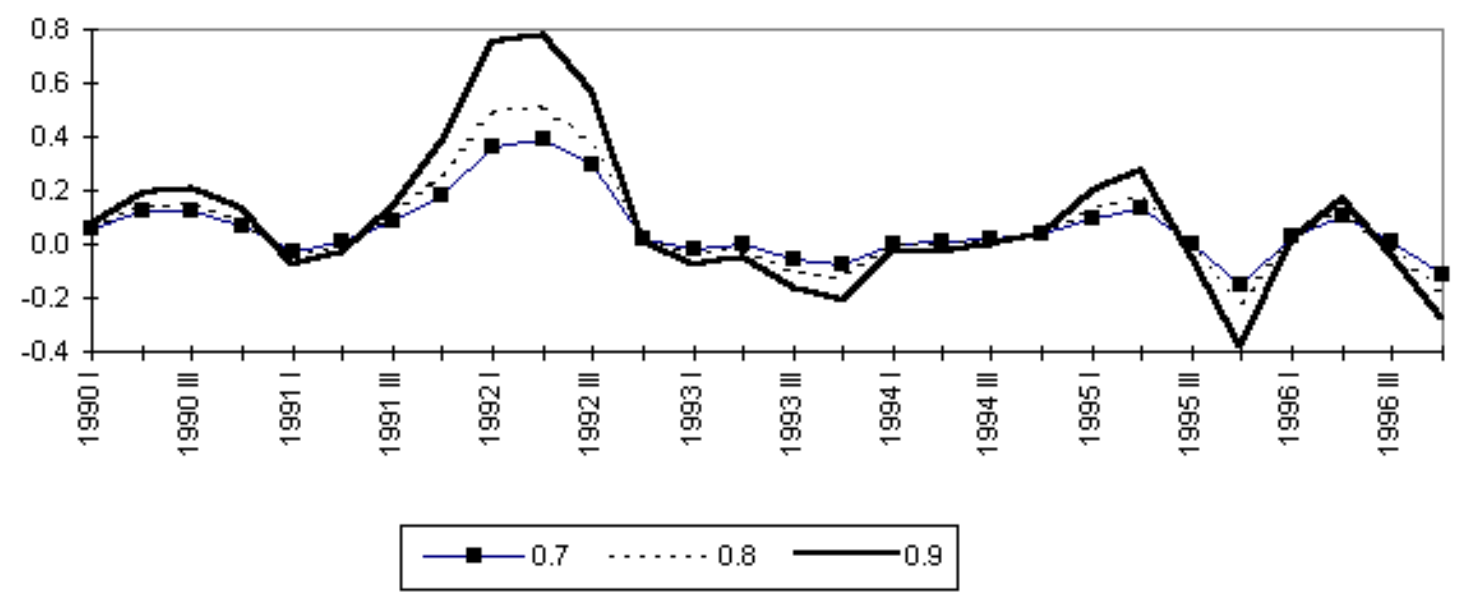

Como era de esperarse, el comportamiento del rendimiento es más suave conforme la razón crédito a valor del bien raíz es menor: existe mayor capital invertido por parte del propietario y las tasas de rendimiento, positivas o negativas, son menores.

A lo largo de la estimación presentada en la gráfica se mantiene constante la razón de crédito a valor del bien raíz. No obstante, durante la expansión crediticia hipotecaria, el enganche requerido como porcentaje del bien a comprar también cambia. Los bancos bajan los requisitos para otorgar crédito conforme la competencia por obtener, o mantener, una mayor participación en el mercado aumenta. El hecho es que la mayor parte de los créditos otorgados se dan con tasas de rendimiento implícitas con un riesgo o volatilidad mayor.

6.2 La Relación entre la Cartera Hipotecaria Vencida y la Razón de Crédito a Valor del Bien Raíz.

En México durante el último trimestre de 1992 y el primero de 1993 se dio un importante aumento en la cartera hipotecaria vencida. El índice de morosidad de pagos pasó de representar $1 \%$ a cerca de 3\% de la cartera hipotecaria total en sólo unos cuantos meses. (El concepto de cartera vencida es el utilizado y reportado hasta finales de 1996. Esta definición incluye solamente las mensualidades atrasadas y no al saldo total del crédito hipotecario que se ha dejado de pagar. En este sentido, el análisis hace énfasis sobre la evolución de la cartera vencida y no sobre su nivel absoluto. A partir de 1997 existe un cambio en la metodología contable incluyéndose en la definición de cartera vencida al saldo total del crédito hipotecario.) El incremento coincidió con un alza en las tasas reales de interés y con una sustancial baja en la tasa de crecimiento del precio de los bienes raíces tomando en cuenta la información de los precios de los terrenos con que se cuenta. En los párrafos que siguen se hace una estimación empírica de la dinámica que tuvo la razón de crédito a valor de la casa $(\mathrm{C} / \mathrm{V})$ y su relación con la cartera hipotecaria vencida. El período de análisis es enero de 1989 a junio de 1995; ya que no se cuenta con una serie de precios de las casas, se recurre al índice de terrenos urbanos de la Ciudad de México y al componente de renta de vivienda del INPC. Hay que advertir que existen otros indicadores de los precios de los bienes raíces, como los publicados en DIME (Publicación dedicada a la "Dinámica del Mercado Inmobiliario" elaborada por Softec S.C. Consultores Inmobiliarios.), que sitúan al pico 
de los precios de los bienes raíces entre mediados de 1993 y finales de 1994. Desafortunadamente no es posible obtener una visión de más largo plazo con estos indicadores. El ejercicio que se presenta a continuación se considera como un primer intento en el que se hace énfasis sobre la necesidad de producir y analizar este tipo de indicadores para estudiar el ciclo inmobiliario.

Para propósitos del análisis siguiente, la razón de crédito a valor de la vivienda se define como:

$\mathrm{RCV}_{\mathrm{t}}=\mathrm{C}_{\mathrm{t}} / \mathrm{V}_{\mathrm{t}}(6.2)$

Donde $\mathrm{V}$ es el precio de la vivienda y $\mathrm{C}$ se refiere al saldo del crédito hipotecario, ambas variables a finales del periodo t. Por lo general, se especifica que RCV depende sólo de un proceso aleatorio: el del precio del bien raíz. Lo anterior se debe a que en la literatura comúnmente se analizan hipotecas a tasa fija, dándose por hecho que el saldo es una función decreciente del tiempo. Para el caso de la llamada hipoteca mexicana, que refinancía una parte de los intereses devengados, cambios en la tasa de interés real también afectarán la evolución de la razón, pues el monto en términos reales del crédito puede incrementarse. Así las cosas, en México la dinámica de RCV está determinada por dos procesos aleatorios, el del precio de la casa y el de la tasa de interés real. Esta característica complica el análisis de la principal variable para explicar el comportamiento de la cartera vencida hipotecaria.

Para hacer un riguroso análisis del comportamiento de la cartera hipotecaria es necesario disponer de información desglosada, con la cual no se cuenta. En este caso se requiere hacer ciertos supuestos sobre el comportamiento de los créditos individuales. Básicamente, se supone que los créditos expedidos en el mismo mes fueron hechos bajo las mismas condiciones.

Con el fin de estimar la razón de crédito a valor de la vivienda $(\mathrm{C} / \mathrm{V})$ se construye el saldo del crédito de la siguiente forma: (Se utilizaron distintos supuestos alternativos para describir la gran variedad de esquemas crediticios existentes en México durante 1989-1995. Por ejemplo, el enganche se incrementó al 20\% y la sobre-tasa de interés se disminuyó a 7 puntos porcentuales. Los resultados fueron similares cualitativamente ya que todos señalaban un incremento sustancial de la probabilidad de moratoria durante 1993. Inclusive un ejercicio adicional, que puede ser más cercano a lo ocurrido, consistió en variar las condiciones crediticias a lo largo del ciclo hipotecario, es decir: ir disminuyendo el enganche requerido, pago inicial etc. Este último ejercicio confirmó los mismos resultados.)

- Para el período de enero de 1989 a junio de 1995 (A partir de julio de 1995 aparecen en los balances consolidados de la Banca Comercial el efecto de la reestructuración de créditos en UDIS.) se calculó para cada mes el monto de crédito hipotecario neto que la banca comercial otorgó en el período. De esta manera se cuenta con un crédito representativo que se inició en enero de 1989, otro en febrero etc., a los cuales se les da seguimiento.

- Los créditos inician con una razón de crédito a precio de la vivienda $(\mathrm{C} / \mathrm{V})$ de 0.85 , es decir un enganche del $15 \%$.

- El pago inicial es de 10 pesos al millar indizándose al INPC. (Esta es una simplificación ya que generalmente los pagos se indizaban a un indicador de salario.)

- La tasa de interés es la máxima entre el CPP y CETES a 28 días; a esta tasa base se adicionan diez puntos porcentuales.

- Es característica de esta hipoteca, tipo "mexicana", que en los primeros años pueda existir un incremento en términos reales del saldo.

Por su parte, el valor de la vivienda se revalúa ya sea a la par del precio de los terrenos o del componente de rentas del INPC.

En la gráfica 6.2 se presenta la cartera vencida y una estimación de los créditos hipotecarios que tendrían capital neto negativo $(\mathrm{RCV}>1)$ bajo el supuesto de que el precio de las casas seguiría la 
dinámica del precio de los terrenos. En estas hipotecas se esperaría que el acreditado ejerciera su opción y tratara de pagar su crédito regresando la casa al banco.

Hay que destacar el incremento sustancial en la proporción de los créditos que se encontraban con capital neto negativo en 1993. Es posible considerar que si se hace este ejercicio con otros indicadores del precio distintos a los precios de los terrenos urbanos en la ciudad de México, este incremento probablemente se empezaría a dar durante 1994.

La gráfica 6.2 supone que la opción de venta de un crédito hipotecario es ejercida automáticamente una vez que RCV $>1$. Una forma alternativa sería suponer una relación no lineal entre la probabilidad de no pago y el capital neto en vivienda. (Véase por ejemplo Case y Shiller (1995) donde se propone una función similar a la utilizada.) En la gráfica 6.3 se presenta un probable candidato: conforme el valor de la razón de crédito a valor de la vivienda se acerca a la unidad la probabilidad de no pago se incrementa a una tasa mayor. La función ha sido especificada de forma tal que exista un $50 \%$ de probabilidad de que no se pague la hipoteca cuando la razón $(\mathrm{C} / \mathrm{V})$ es igual a uno. Una especificación más realista sería el considerar a esta probabilidad cercana al $15 \%$ o $20 \%$. No obstante, el comportamiento de la probabilidad de moratoria a lo largo del tiempo no se modificaría al variar este porcentaje (manteniendo los mismos supuestos sobre la pendiente de la función), sólo el nivel absoluto. Se conserva el $50 \%$ haciendo énfasis en que el objetivo de este ejercicio es la evolución de la probabilidad de no pago y no su valor absoluto. (Se considera que una probabilidad de 15\%$20 \%$ podría ser más realista con base en la función presentada en Case y Shiller (1995). No obstante, con datos agregados no es posible hacer una estimación de este porcentaje. )

\section{GRÁFICA 6.2}

\section{CRÉDITO HIPOTECARIO}

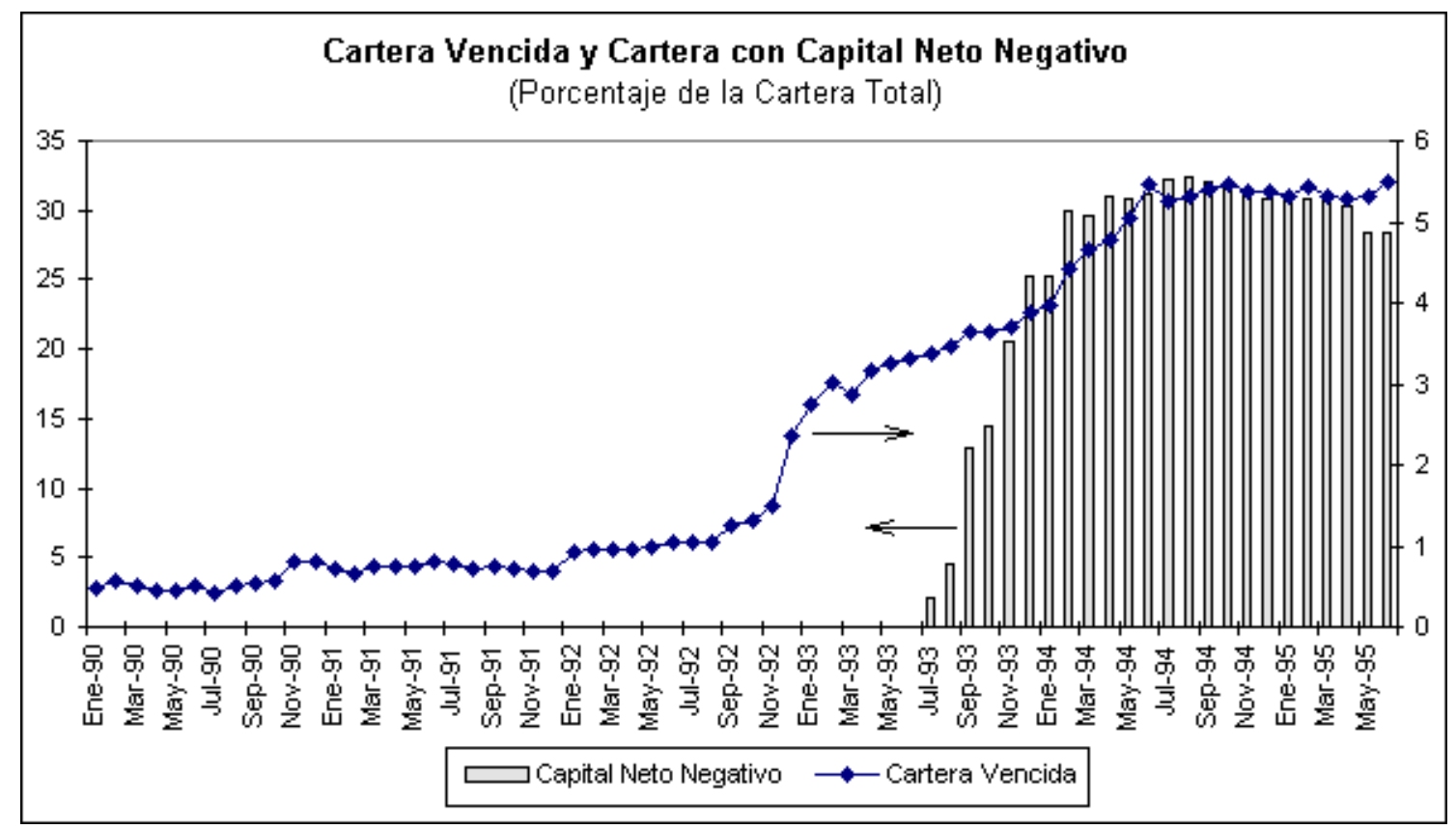




\section{GRÁFICA 6.3}

\section{Función no Lineal entre la Razón Monto de Crédito/Valor de la Vivienda y la Probabilidad de no Pago}

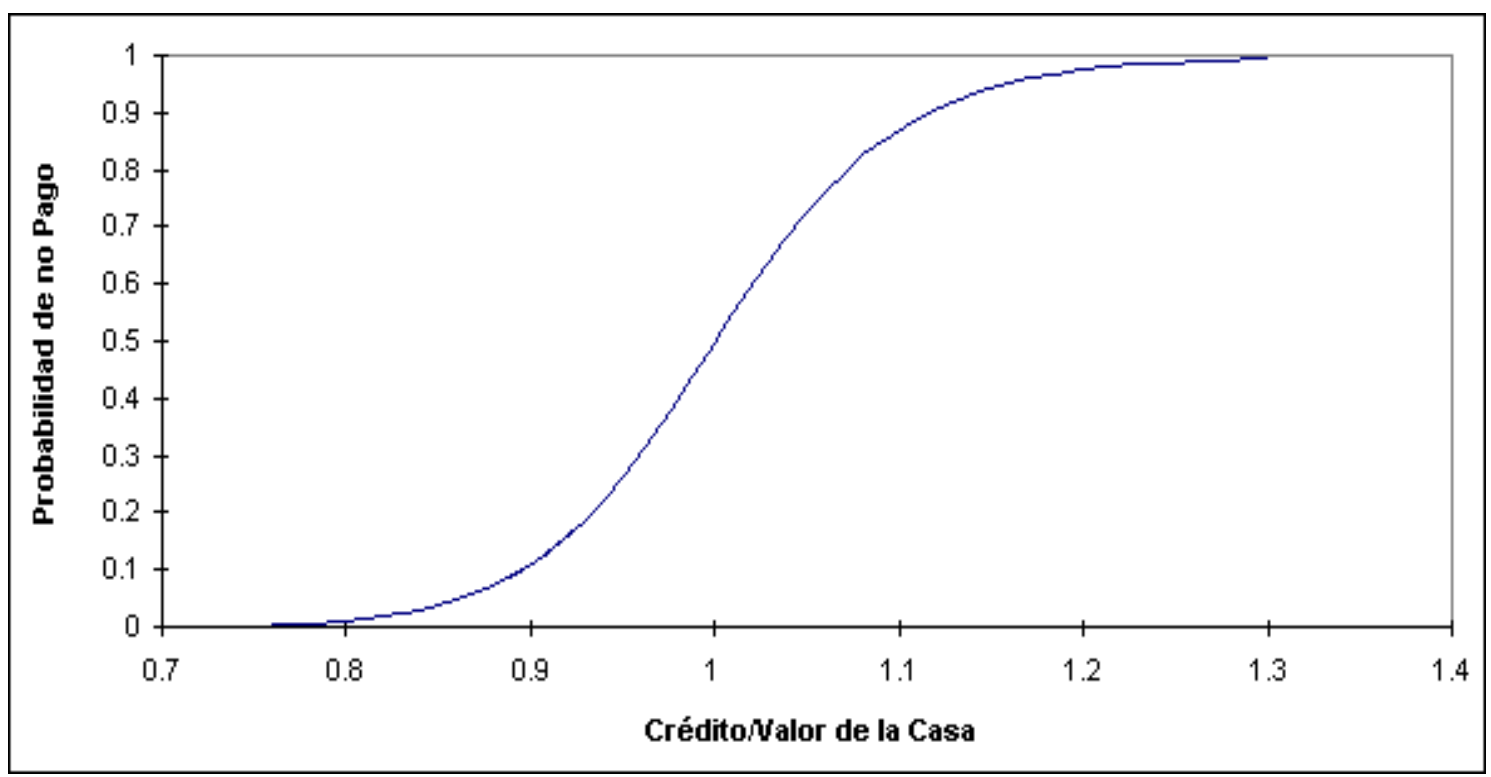

Para obtener un estimado de la probabilidad de no pago se inicia por construir la razón de crédito a valor del bien raíz para el conjunto de los créditos hipotecarios $\left(\mathrm{RCV}_{\mathrm{t}}\right)$. Con este fin, se utiliza la siguiente fórmula:

$$
\text { Promedio } \mathrm{RVC}_{\mathrm{t}}=\Sigma_{\mathrm{s}} \mathrm{RCV}_{\mathrm{t}}^{\mathrm{s}} *\left(\mathrm{C}_{\mathrm{t}}^{\mathrm{s}}\right) / \mathrm{C}_{\mathrm{t}}^{\mathrm{T}}(6.3)
$$

Donde $\mathrm{RCV}_{\mathrm{t}}^{\mathrm{s}}$ es la razón crédito a valor de la vivienda al final del período t de los créditos iniciados en el período $s$ ( $s=$ enero 1989, febrero $1989, \ldots$ junio 1995), $C_{t}{ }^{s}$ es el saldo del crédito iniciado en el periodo $\mathrm{s}$ al final del periodo $\mathrm{t}, \mathrm{y} \mathrm{C}_{\mathrm{t}}^{\mathrm{T}}$ es el saldo total de crédito hipotecario al final del período $\mathrm{t}$. Este cálculo se realiza para cada uno de los meses comprendidos en el lapso enero de 1989 a junio de 1995. Por ejemplo, para el promedio de marzo de 1989 (sólo tres meses después de iniciado el período de análisis) se ponderan las razones correspondientes a los meses de enero, febrero y marzo de 1989, utilizando los saldos de los créditos correspondientes a finales de marzo de 1989.

Una vez obtenido el promedio, se le aplica la función no lineal descrita en la gráfica 6.3 y relacionada con la función de probabilidad logística. El resultado puede ser apreciado en la gráfica 6.4 presentándose bajo los dos supuestos de la dinámica de los precios de las casas, aquél de las rentas de vivienda y de los terrenos urbanos. Se puede constatar que en ambos casos durante 1993 se da un aumento importante en la probabilidad de moratoria de la cartera de crédito hipotecario en su conjunto. El hecho de que la cartera vencida, medida por los pagos atrasados, aumente con antelación a la crisis iniciada en diciembre de 1994 sugiere que el ciclo inmobiliario tuvo su punto más alto durante 1993-1994.

La falta de información no permite hacer una estimación eficiente de la probabilidad de moratoria. No obstante, la aproximación para el agregado apoya la hipótesis de que el valor neto de la casa es la variable fundamental en la decisión de no pago de una hipoteca. Hay que resaltar la omisión del análisis de características económicas del deudor - principalmente variables como el ingreso, estado civil y desempleo- . En la literatura se señala que estas características pueden ser detonantes de la moratoria y modificar la probabilidad de no pago, pero la decisión subyacente esta en función 
del valor del colateral en relación al crédito.

También es importante subrayar que se da un incremento importante en los créditos vencidos antes de la crisis iniciada en diciembre de 1994, y que es frecuentemente señalada como una causa principal de la crisis hipotecaria. Existe evidencia de que al menos parte de la cartera hipotecaria llegó a finales de 1994 con capital neto negativo o cercano a serlo. El problema de la cartera vencida ya se había gestado, la crisis le dio el ambiente para desarrollarse. 


\section{GRÁFICA 6.4}

Cartera Vencida como Porcentaje de la Cartera Total y Probabilidad de no Pago
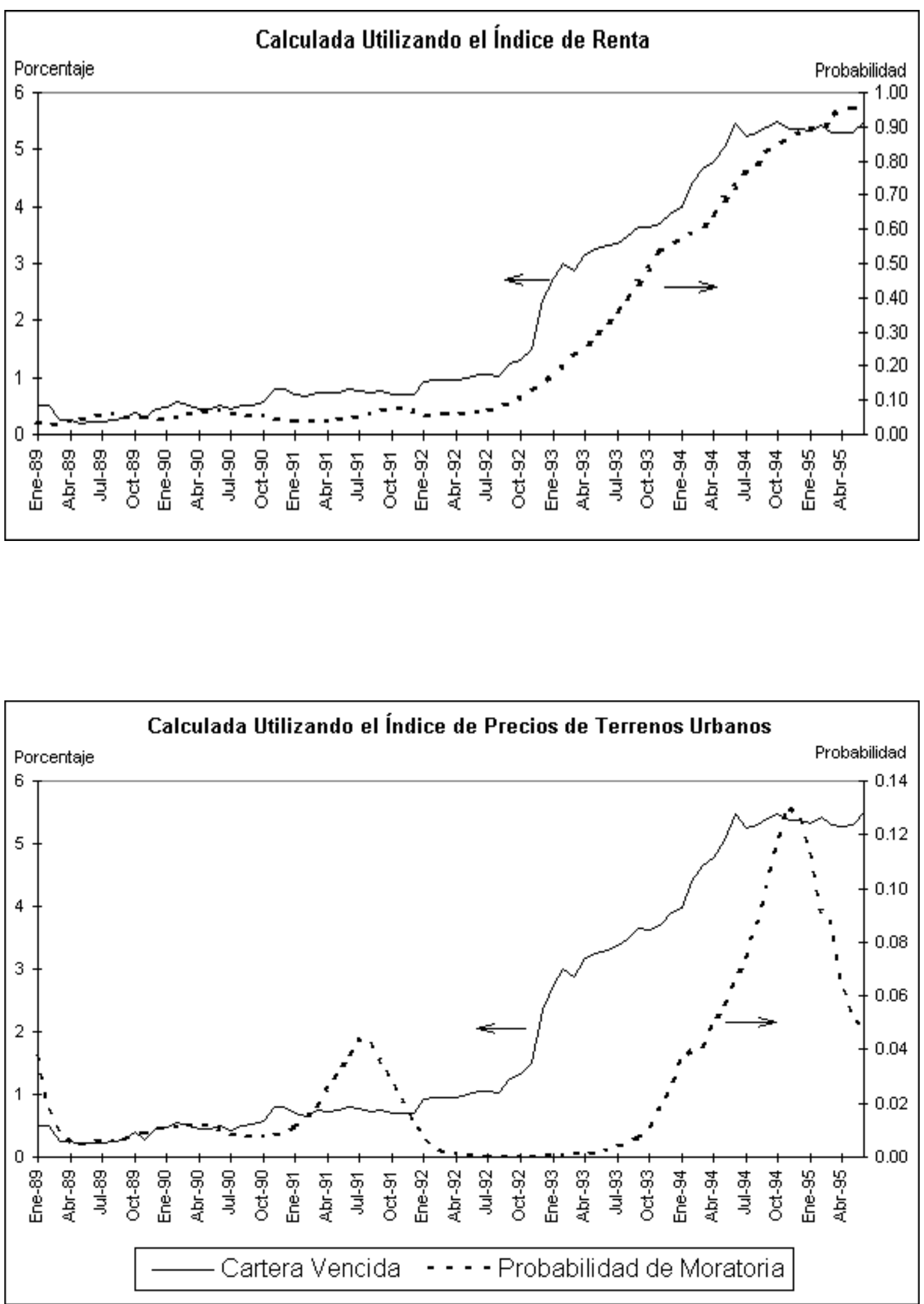


\subsection{La Probabilidad de Moratoria a lo Largo del Ciclo Crediticio.}

Los precios de los bienes raíces tienen un comportamiento cíclico con períodos de incrementos sustanciales y seguidos de bajas también importantes. Analizando la experiencia internacional generalmente se encuentra como antecedente a una crisis hipotecaria, que una parte importante de los créditos se otorgan cuando los precios de las casas comienzan a crecer a tasas menores, a estancarse o inclusive comienzan a bajar. De ahí que sea importante que tanto bancos como autoridades pongan especial atención a los ciclos. Si la razón de crédito a valor de la casa es determinante fundamental de la decisión de pago, entonces la parte del ciclo en que se inicie el crédito es sumamente importante.

A manera de ejemplo, la gráfica 6.5 presenta una estimación hecha sobre la probable evolución del valor de un bien raíz y del saldo de su respectiva hipoteca a lo largo del ciclo. Se hace el supuesto de que se compra un terreno urbano en la Ciudad de México utilizando un crédito con un enganche del $10 \%$. El objetivo de la gráfica es constatar como la fecha del otorgamiento del financiamiento es relevante: dependiendo de la fase del ciclo en que se inicie el crédito el capital neto puede aumentar o disminuir.

Si se compra el terreno en julio de 1991 se alcanzan incrementos de 50\% en términos reales sobre el valor del bien raíz durante el primer año de vida del crédito. Esto crea suficiente capital neto para enfrentar, meses después, un período en el cual el valor del terreno se conserva en términos reales y la hipoteca se incrementa por la subida en las tasas reales de interés. En este caso no se llega a obtener un valor negativo en el capital neto en vivienda ya que el valor del crédito no rebasa al valor del terreno.

Lo descrito en el párrafo anterior es aún cierto si la fecha de compra es diciembre de 1991, pero no si el terreno es comprado siete meses después en julio de 1992. Si se compra el terreno en esta última fecha, para septiembre de 1993 la inversión tiene un valor neto negativo. El valor de la inversión sólo aumentó durante los tres primeros meses de vida del crédito para después disminuir constantemente. Lo mismo es cierto para diciembre de 1992 y julio de 1993 y en menor medida a partir de diciembre de 1993. Los créditos otorgados durante 1994 parecen evolucionar con un capital neto positivo cuando menos hasta mediados de 1995 , no obstante hay que señalar que la probabilidad de no pago esta latente mientras el capital neto sea relativamente pequeño.

En México durante el período 1992-1994 se dio la expansión crediticia hipotecaria más importante de la historia financiera del país. Los también importantes aumentos en el financiamiento hipotecario durante 1995-1996 fueron principalmente el refinanciamiento de los intereses devengados para créditos ya existentes. (Véase la estimación de este refinanciamiento que se presenta en Bernstein, Lea y Renaud (1997). La expansión de crédito hipotecario representó alrededor de 2\% del PIB para 1992-1994 bajando a menos del 1\% en 1995 y 1996 pero incluyendo los programas gubernamentales de financiamiento a vivienda. El crédito hipotecario de la banca comercial durante 1995-1996 no es significativo ya que quitando el refinanciamiento de la cartera hipotecaria ya existente no se dio financiamiento nuevo.) Si los precios de las casas siguieron un ciclo similar al de los terrenos, entonces la mayor parte del crédito hipotecario fue otorgado cuando la probabilidad de no pago era relativamente grande, es decir cuando los créditos hipotecarios obtenían capitales netos negativos aproximadamente al año de haberse iniciado.

Visto desde otra óptica, los esquemas crediticios anteriores a la reestructuración en UDIS de 1995 
suponían implícitamente que el precio de los bienes raíces que servían como colateral se incrementaría a la par cuando menos del aumento esperado en el saldo real del crédito. Tal vez este supuesto se basaba en la fuerte apreciación que tuvieron los bienes raíces en los años anteriores. Aun en el caso de un saldo crediticio constante en términos reales, podría darse capital neto negativo en vivienda si los precios de las casas bajan más de 15\%-20\%. La experiencia internacional y de México, ha demostrado que disminuciones mayores no son raras. De una u otra forma, la evolución del precio del bien raíz debería ser una variable más estudiada y tomada en cuenta. El escaso análisis que se ha hecho sobre el tema contrasta con el tamaño relativo de las crisis hipotecarias. 


\section{GRÁFICA 6.5}

Evolución del Valor de un Crédito Hipotecario y de un Terreno Urbano (en período inicial Terreno=100, Crédito=90)
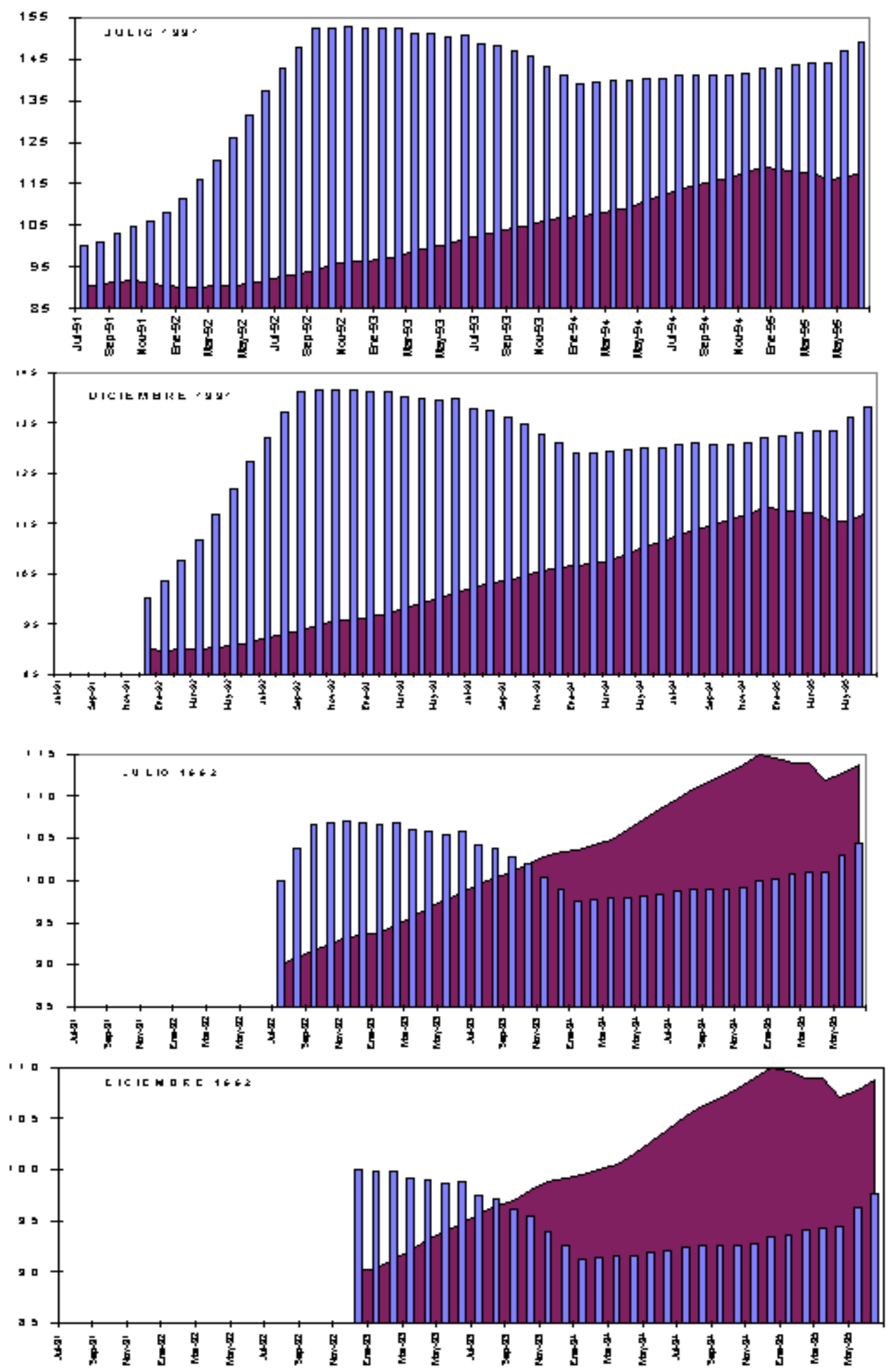

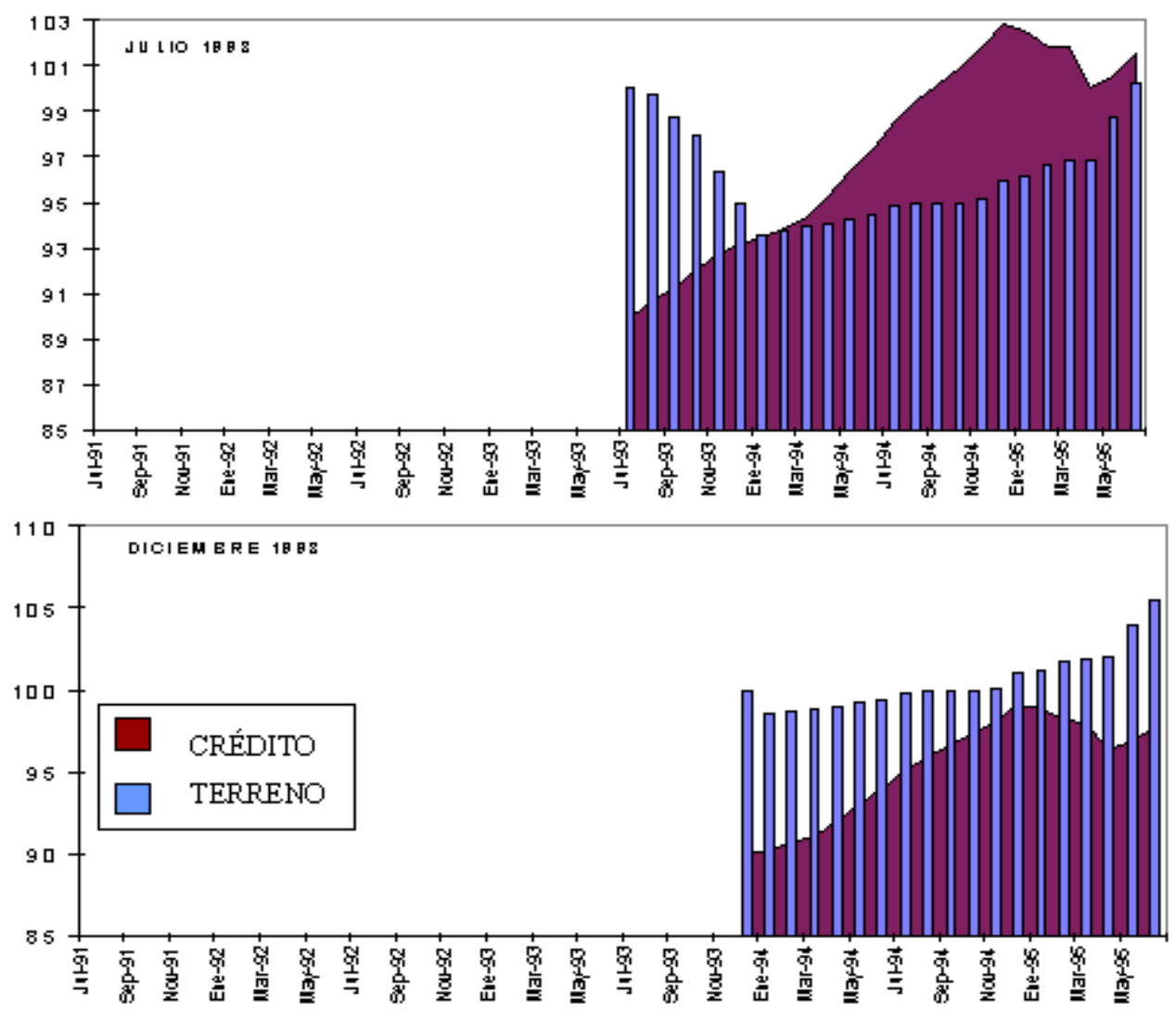

\section{Conclusiones}

La literatura empírica que analiza la cartera vencida hipotecaria señala que el factor determinante de la decisión de moratoria de pago es el valor de la vivienda, neto del monto de la hipoteca. En este sentido, es relevante estudiar tanto la dinámica del saldo de la hipoteca como los precios de las casas. Dadas las características de los esquemas crediticios hipotecarios en México, el aumento en la tasa de interés real a finales de 1992 generó un incremento en el refinanciamiento de los saldos hipotecarios. No obstante, el ciclo de los precios de los bienes raíces también tuvo un papel importante en la gestación del problema de la cartera vencida.

Los precios de los activos inmobiliarios son influidos por variables macroeconómicas. Dada la participación de los bienes raíces en el total de la riqueza de México, cambios en los precios de estos activos tienen repercusiones para la economía en su conjunto. Uno de los canales de mayor relevancia es a través del sistema financiero.

Existe evidencia econométrica de que el precio relativo del arriendo en México está determinado, entre otras variables, por el ingreso y por los flujos de capitales. Sobre esta última variable, se encontró que un incremento de un punto porcentual en la razón de flujos de capital a producto genera un aumento del $13 \%$ en el precio relativo de la renta de vivienda.

Los precios de los bienes raíces son altamente sensibles a los fundamentos. En particular, los precios de los terrenos en la Ciudad de México siguen una tendencia similar a la del arriendo en vivienda, pero con ciclos más pronunciados. Del análisis se desprende que cambios en las variables macroeconómicas, como el ingreso y los flujos de capitales, tendrán un gran efecto sobre el mercado de bienes raíces. Ya que estos últimos sirven de colateral para el sistema financiero, se puede esperar que un contexto de cambios importantes en las variables macroeconómicas puede ser propicio para la gestación de crisis financieras.

En el agregado es posible modelar el comportamiento de la cartera vencida siguiendo la relación de 
crédito a valor del activo. El ejercicio empírico realizado en este trabajo sustenta la hipótesis de que la variable fundamental para explicar la decisión de pago de la hipoteca es el capital neto en vivienda.

Dependiendo de la parte del ciclo en que se encuentren los precios de los bienes raíces, existirá una mayor o menor probabilidad de suspensión de pagos. Es importante señalar que se da un incremento en los créditos vencidos, mucho antes de la crisis iniciada en diciembre de 1994. Frecuentemente esta última es señalada como la causa principal del problema hipotecario. Sin embargo, una parte de la cartera hipotecaria llegó a finales de 1994 con capital neto negativo o cercano a serlo. El problema de la cartera vencida ya se había gestado, la crisis le dio el ambiente en el cual desarrollarse.

Los créditos que incluyan potencialmente cualquier tipo de refinanciamiento en términos reales implícitamente están suponiendo un aumento en el precio del colateral, similar al que se va a dar en el saldo hipotecario. Dada una dinámica del precio del bien raíz, estos créditos son más riesgosos. La probabilidad de incurrir en capital neto negativo es mayor ya que el saldo hipotecario, en términos reales, se puede incrementar.

El país en su conjunto no cuenta con instituciones que puedan cubrir el riesgo sistémico que implica una baja sustancial en el precio de los bienes raíces, los cuales representan una tercera parte de nuestra riqueza. La construcción y análisis de indicadores de los precios de casas es el primer paso para la conformación de un mercado de futuros de precios de bienes raíces.

\section{Referencias}

Barry, Christopher B., Gonzalo Castañeda, and Joseph B. Lipscomb (1994) "The structure of mortgage markets in México and prospects for their securitization" Journal of Housing Research Fannie Mae, pág. 174-203.

Bernstein, Steve A., Michael Lea, y Bertrand Renaud (1997) "Mexico's housing finance system 1991-96, privatization in an unstable enviroment" Documento presentado en la Conferencia Internacional de la AREUEA. Cardiff Consulting Services y el Banco Mundial, mayo de 1997.

Booth, G., J. Glascock, T. Martikainen, y T. Rothovius (1994) "The financing of residential real estate in Finland: an overview" Journal of Housing Research vol. 5, núm. 2, pág. 205-227.

Case, Karl E., Allan N. Weiss, y Robert J. Shiller (1995) "Mortgage default risk and real estate prices: the use of indexbased futures and options in real estate" Serie NBER Working Paper núm. 5078 , abril 1995.

Cervini, Hector (1995) "El costo de oportunidad de los fondos públicos en México" México: Departamento de Economía . Universidad Autónoma Metropolitana-Azcapotzalco.

Chou, W.L., y Y.C. Shih (1995) "Hong Kong housing markets: overview, tenure choice, and housing demand" Journal of Real Estate Finance and Economics, núm.10. pág. 7-21. 
Deng, Yongheng, John M. Quigley y Robert Van Order (1997) "Mortgage terminations, heterogeneity and the exercise of mortgage options" Documento presentado en la Conferencia Internacional de la AREUEA. Office of Federal Housing Enterprise Oversight, University of California at Berkeley, Freddie Mae, mayo de 1997.

DiPascale, D. y W. Wheaton (1996) "Urban economics and real estate markets", New Jersey: Prentice-Hall.

Froot, Kenneth A., y Maurice Obstfeld (1991) "Intrinsic bubbles: the case of stock prices" The American Economic Review, vol. 81, núm. 5, pág. 1189-1214.

Grau, C., Nelson Maya y Martín Rama (1987) "El precio de la vivienda, consecuencias contables y efectos macroeconómicos" Suma, núm. 2, pág. 26-46, Montevideo.

Green, William H. (1993) "Econometric analysis" Segunda Edición . Macmillan-Nueva York.

Guerra de Luna, Alfonso H. (1997) 'Residential real estate booms, financial deregulation and capital inflows: an international perspective" Documento presentado en la Conferencia Internacional de la AREUEA. Banco de México, mayo de 1997.

Hamilton, Bruce W., (1991) "The baby boom, the baby bust, and the housing market: a second look" Regional Science and Urban Economics, vol. 21, North Holland, pág. 547-552.

Harberger, Arnold C. (1969) "La tasa de rendimiento en Colombia" Colombia, Departamento Nacional de Planeación , Revista de Planeación y Desarrollo, octubre de 1969.

Harberger, Arnold C. (1988) "Growth, Industrialization and Economic Structure: Latin America and East Asia Compared" en Achieving industrialization in East Asia editado por Helen Hughes, serie Trade and development Cambridge, Nueva York

Harberger, Arnold C. (1994) "On loanable funds, liquidity preference and the monetary approach: some lessons I have learned" Documento preparado para la "Memorial Conference on the Economic Thought of Professor S.C. Tsiang". Taipei, Taiwan . Noviembre de 1994.

Holmans, A.E.,(1994) "House prices, land prices, the housing market and house purchase debt in the UK and other countries" Economic Modelling, Número especial: Financial liberalization and housing market dynamics, Holly, S. y A. Milne (eds.) vol. VII, pág. 157-200.

Kau, J. D. Keenan y T. Kim (1991) "Default probabilities for mortgages" Department of Insurance, Legal Studies and Real Estate, The University of Georgia. Mimeo.

Kim, Kyung-Hwan. (1993) "Housing prices, affordability, and government policy in Korea", Journal of Real Estate Finance and Economics, núm. 6, pág. 55-71. 
Kim, Kyung-Hwan y Seoung Hwan Suh (1993) "Speculation and price bubbles in the Korean and Japanese real estate markets" Journal of Real Estate Finance and Economics, núm. 6, pág. 73-87.

Lea, Michael J.(1995) "Housing finance in Mexico: a 1995 update"Housing Finance International, vol. IX, núm. 18-20.

Lin, Chu-Chia Steve. (1993) "The relationship between rents and prices in owner-occupied housing in Taiwan", Journal of Real Estate Finance and Economics, núm. 6, pág. 25-54.

Maydón, Marín (1988) "La inflación y el financiamiento para la vivienda. Precios relativos y nuevos sistemas de pagos" Comercio Exterior Vol. 38., núm. 10, pág. 911-922.

Miles, David K. ( 1994) "Housing, financial markets and the wider economy", Gran Bretaña: Wiley.

Morande, Felipe (1992)" The dynamics of real asset prices, the real exchange rate, trade reforms and foreign capital inflows, Chile 1976-1989" Journal of Development Economics, núm. 39, pág. 111-139.

Morande, Felipe y Raymundo Soto (1992) "Una nota sobre la construcción de series de precios de activos reales: tierra y casas en Chile 1976-1979" Revista de Análisis Económico, vol.7, pág. 169-177.

Muellbauer, J. y A. Murphy (1996) "Booms and busts in the UK housing market" Serie Economic Discussion Paper, Nuffield College Oxford, núm. 125.

Murillo, José A. (1991) "Dinamica del alquiler de vivienda en México" Banco de México, Mimeo.

Muth, Richard F. (1988) "Theoretical issues in housing market research" en The economics of housing markets por Richard F. Muth y Allen c. Goodmand, de la serie Fundamentals of pure and applied economics. Harwood Academic Publishers, Reino Unido.

Quercia, Roberto G., y Michael A. Stegman (1992) "Residential mortgage default: a review of the literature" Journal of Housing Research. vol. 3, núm. 2, pág. 341-379.

Sánchez, Abdón (1995) "Esquemas de reestructuración de pasivos ante diversos escenarios de tasas de interés y de inflación" Serie Documentos de Investigación núm. 9503, Banco de México. Julio de 1995.

Shiller, Robert J. (1993) "Macro markets. Creating institutions for managing society's largests economic risks" Clarendon Press-Oxford. 


\section{Pruebas de Raíces Unitarias para Variables de la Sección 4}

\begin{tabular}{|c|c|c|c|c|}
\hline \multirow[t]{2}{*}{ Variable/Prueba } & \multicolumn{2}{|c|}{$\begin{array}{c}\text { Prueba de Dickey-Fuller } \\
\text { Aumentada }\end{array}$} & \multicolumn{2}{|c|}{ Prueba de Phillips-Perron } \\
\hline & Estadístico DFA & Valor Critico & Estadístico PP & Valor Critico \\
\hline $\begin{array}{c}\text { Acervo de } \\
\text { Vivienda }\left(\mathrm{H}_{\mathrm{t}}\right)\end{array}$ & -2.49 & $\begin{array}{l}1 \%-3.73 \\
5 \%-2.99 \\
10 \%-2.63\end{array}$ & -3.58 & $\begin{array}{l}1 \%-4.37 \\
5 \%-3.60 \\
10 \%-3.23\end{array}$ \\
\hline $\begin{array}{c}\text { Ingreso } \\
\text { Permanente }\left(\mathrm{Y}_{\mathrm{pt}}\right)\end{array}$ & -1.19 & $\begin{array}{l}1 \%-2.68 \\
5 \%-1.96 \\
10 \%-1.62\end{array}$ & -2.32 & $\begin{array}{l}1 \%-3.76 \\
5 \%-3.01 \\
10 \%-2.64\end{array}$ \\
\hline $\begin{array}{c}\text { Renta de } \\
\text { Vivienda }\left(R_{t}\right)\end{array}$ & -2.26 & $\begin{array}{l}1 \%-3.73 \\
5 \%-2.99 \\
10 \%-2.63\end{array}$ & -1.71 & $\begin{array}{l}1 \%-3.72 \\
5 \%-2.98 \\
10 \%-2.63\end{array}$ \\
\hline $\begin{array}{c}\text { Acervo de } \\
\text { Vivienda per } \\
\text { Capita }\left(\mathrm{H} / \mathrm{POB}_{\mathrm{t}}\right)\end{array}$ & -3.13 & $\begin{array}{l}1 \%-4.39 \\
5 \%-3.61 \\
10 \%-3.24\end{array}$ & -2.48 & $\begin{array}{l}1 \%-4.44 \\
5 \%-3.63 \\
10 \%-3.25\end{array}$ \\
\hline $\begin{array}{c}\text { Ingreso } \\
\text { Permanente per } \\
\text { Capita }\left(\mathrm{Y}_{\mathrm{p}} / \mathrm{POB}_{\mathrm{t}}\right)\end{array}$ & -2.67 & $\begin{array}{l}1 \%-3.78 \\
5 \%-3.01 \\
10 \%-2.64\end{array}$ & -2.37 & $\begin{array}{l}1 \%-3.77 \\
5 \%-3.01 \\
10 \%-2.64\end{array}$ \\
\hline $\begin{array}{c}\text { Transferencia } \\
\text { Neta de Recursos } \\
\text { como Porcentaje } \\
\text { del Producto } \\
\left(\mathrm{TNR} / \mathrm{PIB}_{\mathrm{t}}\right)\end{array}$ & -2.63 & $\begin{array}{l}1 \%-2.66 \\
5 \%-1.96 \\
10 \%-1.62\end{array}$ & -2.26 & $\begin{array}{l}1 \%-2.66 \\
5 \%-1.95 \\
10 \%-1.62\end{array}$ \\
\hline $\begin{array}{l}\text { Residuales de la } \\
\text { estimación } \\
\text { reportada en la } \\
\text { Cuadro } 3.1\end{array}$ & -3.46 & $\begin{array}{l}1 \%-2.71 \\
5 \%-1.96 \\
10 \%-1.63\end{array}$ & - & - \\
\hline $\begin{array}{l}\text { Residuales de la } \\
\text { estimación } \\
\text { reportada en la } \\
\text { Cuadro } 3.3\end{array}$ & -3.46 & $\begin{array}{l}1 \%-2.71 \\
5 \%-1.96 \\
10 \%-1.63\end{array}$ & - & - \\
\hline
\end{tabular}


Pruebas de Raíces Unitarias para la Sección 5

\begin{tabular}{|c|c|c|c|c|}
\hline Variable/Prueba & \multicolumn{2}{|c|}{$\begin{array}{c}\text { Prueba de Dickey-Fuller } \\
\text { Aumentada }\end{array}$} & \multicolumn{2}{c|}{ Prueba de Phillips-Perron } \\
\hline & Estadístico DFA & Valor Critico & Estadístico PP & Valor Critico \\
\hline Log (Renta) & -2.33 & $1 \%-3.49$ & -1.75 & $1 \%-3.49$ \\
& & $5 \%-2.89$ & & $5 \%-2.89$ \\
& & $10 \%-2.58$ & & $10 \%-2.58$ \\
\hline Log (Precio & -1.95 & $1 \%-3.49$ & -1.47 & $1 \%-3.49$ \\
Terrenos) & & $5 \%-2.89$ & & $5 \%-2.89$ \\
& & $10 \%-2.58$ & & $10 \%-2.58$ \\
\hline Log (Precio & -1.64 & $1 \%-3.49$ & -1.64 & $1 \%-3.49$ \\
Terrenos/Renta) & & $5 \%-2.89$ & & $5 \%-2.89$ \\
& & $10 \%-2.58$ & & $10 \%-2.58$ \\
\hline $\begin{array}{c}\text { Log (Precio } \\
\text { Terrenos) - Log } \\
\text { (Renta) }\end{array}$ & -1.64 & $1 \%-3.49$ & -1.51 & $1 \%-3.49$ \\
& & $5 \%-2.89$ & & $5 \%-2.89$ \\
\hline
\end{tabular}




\section{Pruebas de Causalidad de Granger para la Sección 5}

Variables: Precios de Terrenos y Renta de Vivienda en Primeras Diferencias

\begin{tabular}{|l|c|c|}
\hline Prueba de Causalidad de Granger & \\
Muestra: 1970.01: 1996.04 & & \\
Rezagos: 2 & Observaciones & Estadístico F \\
\hline Hipótesis Nula & 105 & 3.78951 \\
\hline Los cambios en Rentas no causan a los cambios en Terrenos & & 1.75472 \\
\hline Los cambios en Terrenos no causan a los cambios en Rentas & & \\
\hline
\end{tabular}

